\title{
Tetrahedral chalcopyrite quantum dots in solar-cell applications
}

\section{Juho Ojajärvi}

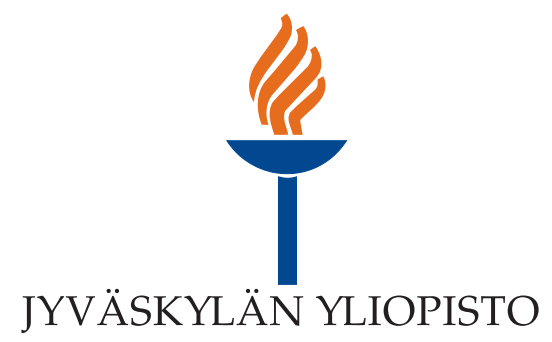

Master's thesis

University of Jyväskylä, Department of Physics

22.12.2010

Supervisor: Academy Research Fellow Esa Räsänen 


\section{Contents}

1 Preface 1

2 Johdanto 2

$\begin{array}{llr}3 & \text { Introduction } & 3\end{array}$

4 Solar energy generation $\quad 4$

4.1 Three generations of photovoltaics . . . . . . . . . . . . . . 4

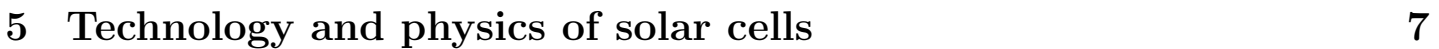

5.1 Monocrystalline silicon solar cells . . . . . . . . . . . . . 8

5.2 Tandem solar cells . . . . . . . . . . . . . . . . . . 8

5.3 Dye-sensitized solar cells . . . . . . . . . . . . . . . . . . . 9

5.4 Hot carrier solar cells . . . . . . . . . . . . . . . . . . . . . . . . . . . . . . . . . . . .

5.5 Intermediate-band solar cells . . . . . . . . . . . . . . . 11

5.5.1 Efficiency of an ideal intermediate-band solar cell . . . . . 12

6 Quantum dots $\quad \mathbf{1 6}$

6.1 Applications in intermediate-band solar cells . . . . . . . . . . . 16

6.2 Chalcopyrite quantum dots . . . . . . . . . . . . . . . . . 18

6.2.1 Tetrahedral chalcopyrite nanostructures . . . . . . . . . 19

7 Theoretical methods $\quad 22$

7.1 Effective mass approximation . . . . . . . . . . . . . . . 22

7.2 Density-functional theory . . . . . . . . . . . . . . . . . 23

7.2.1 Exchange and correlation . . . . . . . . . . . . . . 24

7.3 Time-dependent density functional theory . . . . . . . . . . . . . 26

7.4 Optical response from linear-response . . . . . . . . . . . . . . 27

7.4.1 Casida formalism . . . . . . . . . . . . . . . 27

7.4 .2 Sternheimer formalism . . . . . . . . . . . . . . 28

7.5 Optical response from direct time-evolution . . . . . . . . . . . . 28

7.6 Numerical methods . . . . . . . . . . . . . . . . . . . . . . . . . . 29

7.6.1 Computational details . . . . . . . . . . . . . 29

8 Results $\quad 30$

8.1 Optimal efficiency . . . . . . . . . . . . . . . . . . . . 32

8.2 Realistic model . . . . . . . . . . . . . . . . . . . . . 32

8.3 Size optimization . . . . . . . . . . . . . . . . . . . 35

8.3.1 ZnSe $/ \mathrm{CuGaSe}_{2} \ldots \ldots \ldots \ldots \ldots \ldots$

8.3.2 $\mathrm{CuGaSe}_{2} / \mathrm{CuInSe}_{2} \ldots \ldots \ldots \ldots \ldots . \ldots . \ldots . \ldots . \ldots$ 
8.4 Geometric effects of the chalcopyrite dot . . . . . . . . . . . 38

8.5 Optical spectra of tetrahedral quantum dots of differing electron numbers . . . . . . . . . . . . . . . . . 40

8.6 Band structure of stacked quantum dots . . . . . . . . . . . . . . 43

9 Summary 


\section{Preface}

This master's thesis presents the concluding chapter of my studies for the master's degree in physics in the University of Jyväskylä. I would like to thank all my friends, fellow students and especially Minna for providing me with support and coffee. Special thanks belong to Dr. Esa Räsänen who was my supervisor.

I would also like to thank the Fortum Foundation for financial support to the project, which enabled us to initiate the project, visit Helmholtz Zentrum in Berlin and invite Dr. Sascha Sadewasser for a visit to Jyväskylä. This was advantageous for our understanding of the experimental side of physics, and hopefully provided the experimentalists some insight into the computational work done by our group.

Juho Ojajärvi 


\section{Johdanto}

Aurinkokennoteknologialla tulee olemaan huomattava vaikutus yhteiskuntiin tulevina vuosina, jos vain onnistumme kehittämään riittävän kustannustehokkaita ratkaisuja. Jotta kustannustehokkaita ratkaisuja löydettäisiin, tulee tehdä paljon perustutkimusta aurinkokennomateriaalien ja niissä tapahtuvien kvantti-ilmiöiden saralla. Koska useimmat kvanttimekaaniset järjestelmät ovat hyvin vaikeita tarkastella käyttäen vain kynää ja paperia, tarvitaan laskennallisen kvanttimekaniikan apua. Laskennallinen kvanttimekaniikka tarjoaa työkaluja kuten tiheysfunktionaaliteoria, joiden avulla voidaan saada käsitys syistä ja seurauksista monimutkaisissakin järjestelmässä.

Käsittelemme erästä mahdollista tulevaisuuden aurinkokennoteknologiaa, välivyöaurinkokennoa, ja laskuja liittyen tällaisen teknologian toteutukseen. Välivyöaurinkokennon teoreettinen tehokkuusmaksimi on huomattavasti korkeampi kuin tavallisilla piikennoilla ( $63.2 \%$ vs. $40.7 \%$ ), jotka edelleen muodostavat suurimman osan maailman aurinkokennotuotannosta. Vuonna 1997 esitellyn idean keksijöitä ovat espanjalaiset fyysikot Antonio Martí ja Antonio Luque. Nykyään maailmassa on useita ryhmiä, jotka kehittävät välivyöaurinkokennoja. Eräs näistä ryhmistä sijoittuu Saksaan Berliinin Helmholtz-keskukseen, ja tämä gradu on tehty yhteistyössä heidän kanssaan.

Välivyöaurinkokennon rakentaminen osoittautui melko vaikeaksi ja vasta viime vuonna onnistuttiin rakentamaan ensimmäinen toimiva laite: happiseostettu ZnTe-pohjainen välivyöaurinkokenno, joka tuottaa 100\% suuremman oikosulkuvirran ja 50\% suuremman kokonaistehokkuuden verrattuna tavalliseen ZnTeaurinkokennoon. Välivyöaurinkokenno näyttää tämän onnistumisen myötä entistä lupaavammalta tutkimuskohteelta.

Gradu käsittelee lähinnä välivyöaurinkokennon kvanttipistepohjaista toteutusta. Kvanttipisteet ovat pienitilavuuksisia potentiaalikuoppia, jotka aiheuttavat kvanttipisteessä olevan elektronin energian kvanttittumisen. Riittävän virheettömällä, tiuhalla ja järjestyneellä kvanttipistehilalla voidaan luoda välivyö tavalliseen puolijohdeaurinkokennoon. Kvanttipistemateriaalin ja aurinkokennomateriaalien sähköisten ominaisuuksien täytyy myös sopia yhteen tietyllä tavalla. Tässä työssä keskityimme kalkkipyriittikvanttipisteisiin sinkkiseleeni- ja kalkkipyriittiaurinkokennoissa.

Olemme saaneet selville kalkkipyriittiaurinkokennojen maksimitehokkuusarvoja ja kalkkipyriittikvanttipisteiden optimikoot. Lisäksi saimme tietoa kalkkipyriittikvanttipisteiden optisista absorptiospektreistä ja kalkkipyriittikvanttipisteen geometrian vaikutuksesta sen energiatiloihin. Allekirjoittanut on saanut reilusti lisää kokemusta ja tietoa kvanttinanorakenteiden simuloinnista. 


\section{Introduction}

Solar-cell technology will have an impact on whole societies and billions of people in the coming years, if only we are able to develop more efficient and affordable solutions. This requires precise knowledge about solar-cell materials and quantum phenomena in them. Since most quantum systems are very hard to analyze with pen and paper or with experimental techniques, computational quantum physics can provide significant insight. It offers tools such as density-functional theory (DFT) which enables us to compute quantum phenomena efficiently even in complex systems.

This master's thesis concentrates on DFT calculations connected to one potential future solar-cell technology: intermediate-band solar cells (IBSCs). These devices were first envisioned by Spanish physicists Antonio Martí and Antonio Luque in 1997 and have been studied in many research groups since. IBSCs have the potential to significantly exceed the efficiency of conventional silicon single-gap solar cells (63.2\% vs. $40.7 \%)$ [1].

The realization of a working IBSC has been hard and most attempts have failed. But recently there has been significant success, a ZnTe:O-based IBSC which demonstrates a $100 \%$ increase in short circuit current and overall $50 \%$ increase in power conversion efficiency over conventional undoped ZnTe diodes has been achieved. The potential of the IBSC-technology has been confirmed after years of research [2].

The emphasis of the thesis is on the quantum-dot approach to implement the intermediate bands. Quantum dots are potential wells that lead to quantization effects. With sufficiently defect-free, tight, and thick stacks of quantum-dot arrays of the right geometry, it is possible to introduce an intermediate band into the host material such as chalcopyrite to boost the efficiency of the diode. The electronic properties of the matrix material and quantum-dot material also have to match in a certain way. Here we have concentrated on chalcopyrite materials.

We have obtained maximum efficiency values of chalcopyrite IBSCs and optimal sizes of chalcopyrite quantum dots. In addition, we now have more knowledge about the optical absorption spectra of chalcopyrite quantum dots and the effect of geometry on the energy levels of chalcopyrite quantum dots. The author of the thesis has accumulated lots of useful experience and knowledge about simulation of quantum nanostructures. 


\section{Solar energy generation}

Solar energy generation, from the physics point of view, is simply conversion of photons originated from the Sun into voltage and current carriers, i.e., electrons and electron holes. This can be done indirectly using thermal power generators or directly using photovoltaics.

The photovoltaic power industry is experiencing dramatic technology advances and market growth. Over the past 20 years, manufacturing output has grown by a factor of 200 to $5 \mathrm{GW}$. This is still small in comparison to the world total electric generation capacity of $4000 \mathrm{GW}$, but represents a large step forward in this promising renewable energy technology. If the present rate of growth continues, photovoltaic solar power will be the dominating power generation method by the end of the century [3].

\subsection{Three generations of photovoltaics}

There are three generations of solar cells. First-generation solar cells comprise of technologies where the photon absorber is a thin (a few hundred micrometres) p-doped single crystal silicon wafer. Employing silicon for this purpose is understandable in view of its abundance, stability, non-toxicity, and decades of industry experience. However, single-crystal silicon wafers are very expensive to produce due to the demands of high purity and high accuracy of sawing a single wafer from silicon. The limitations of silicon are also well known. A fundamental constraint on the open-circuit voltage and the efficiency of a silicon solar cell is imposed by the Auger recombination processes [4]. The proposed practical bound on cell efficiency under one-sun illumination (no concentration of sunlight) has been estimated as $25 \%$.

Second-generation solar cells aim at reducing the costs of producing thin-film solar cells by growing thin layers of silicon and other semiconductors on glass substrates. Materials such as cadmium telluride ( $\mathrm{CdTe}$ ), copper-indium-gallium selenide (CIGS), copper-indium sulphide (CIS) and amorphous silicon (a-Si) are used. This is much cheaper than using single-crystal silicon but has the downside of leading to less efficient solar cells due to structural defects [5].

Third-generation solar cells consist of all the technologies with an aim to exceed the theoretical efficiency of single-gap solar cells. Examples of such technologies are

- $\quad$ intermediate-band solar cells

- tandem or multi-junction solar cells

- $\quad$ solar cells manufactured of exotic non-semiconductor photovoltaic materials (organic materials, polymer cell-structures, etc.) 
- $\quad$ solar cells incorporating silicon or other semiconductor nanostructures - hot carrier cells

The categorization of the multitude of the present technologies available is not clear. Many of the latest newer solar-cell technologies combine different approaches in novel ways.

Efficiencies of some of these different technologies can be seen in Fig. 1. The efficiency record of the first-generation silicon solar cells now stands at $27.6 \%$. The best efficiency achieved with second-generation thin-film chalcopyrite solar cells is $20.0 \%$. The overall best are at the moment the third-generation multijunction solar cells with an efficiency of $41.6 \%$.

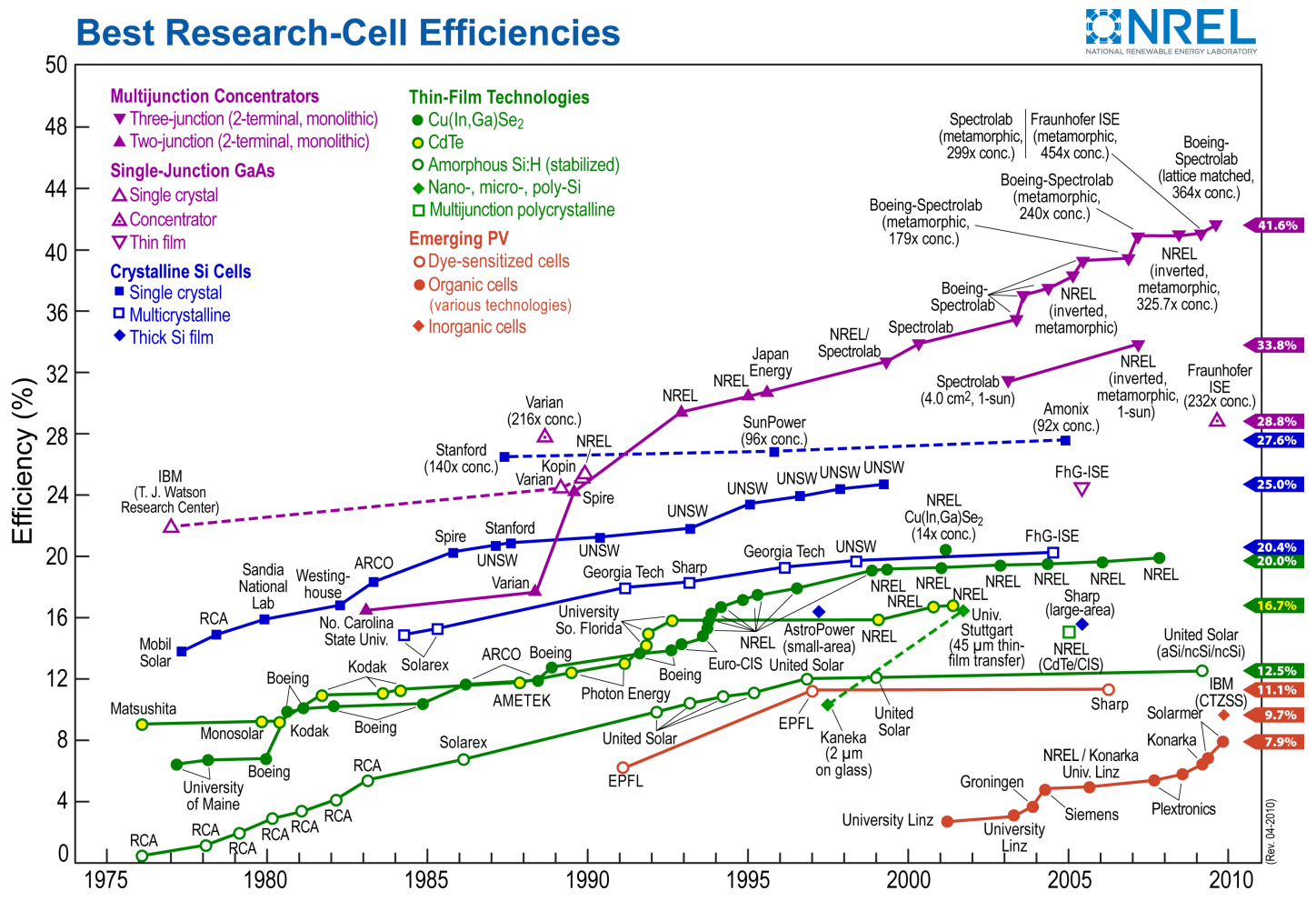

Figure 1: Development of the best solar cell efficiencies (From Ref. [6]).

The cost per Watt of the different technologies varies considerably. Figure 2 shows the approximate cost for different solar cell generations. First-generation cells are somewhat efficient but expensive. Second-generation cells are cheaper but less efficient. Third-generation devices made from more advanced technologies and materials are at an earlier stage of development but could provide high efficiencies at low costs, especially in conjunction with concentrator mirror technology. Figure 2 shows also (i) the Shockley-Queisser limit, which is the theoretical efficiency of a perfect single-junction photovoltaic solar cell, and (ii) the ultimate 
thermodynamic limit without solar light concentration, and (iii) the ultimate thermodynamic limit with maximum solar light concentration.

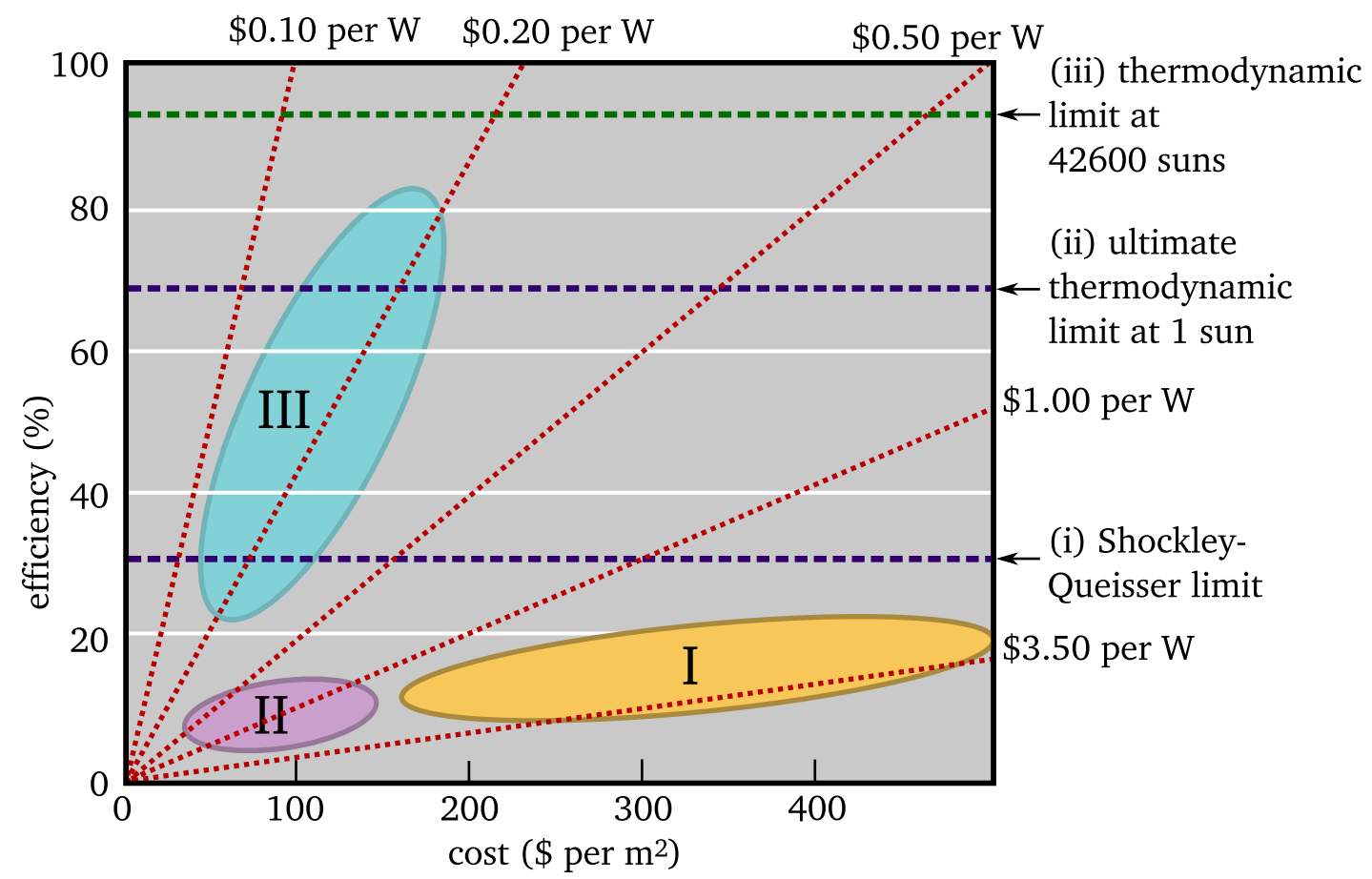

Figure 2: Efficiency versus price per Watt for the three generations (I, II, and III) of solar cells from Ref. [5]. The dashed diagonal lines denote points of constant cost per unit power, measured in dollars per peak watts. 


\section{$5 \quad$ Technology and physics of solar cells}

The basic component of most photovoltaic devices is the p-n junction which is the boundary interface between a positively and a negatively doped semiconductor block, i.e., the boundary interface of a diode. Many such semiconductor diodes exhibit the photovoltaic effect.

When photons hit the electrons of the p-n junction and charge them to the conduction band, two charge carriers are generated: an electron in the conduction band and a hole in the valence band. These two charge carriers must be separated in order to prevent recombination and to generate a current.

In photodiodes like those that are used in very common polycrystalline silicon solar cells, the charge-carrier separation is realized by the internal electric field of the diode. The depletion region field is formed in the p-n junction between positively and negatively doped semiconductors. Electrons and holes combine near the interface of two materials to create a depletion region of charge carriers. In this region an electric field is then created by the ionized dopants. The electric field has the effect of sweeping the photogenerated negatively charged electrons and positively charged holes to different sides of the junction, thus preventing recombination [7]. The whole process is visualized in Fig. 3.

a)

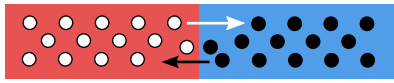

b)

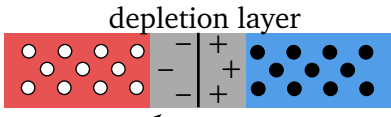

electric field

c)

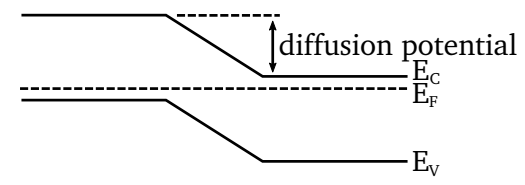

d)

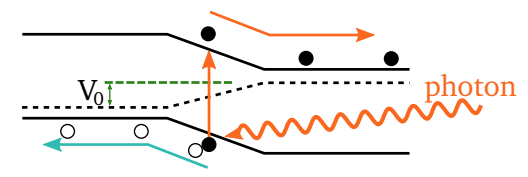

FIGURE 3: (a) p-n junction of a positively and a negatively doped semiconductor block [8]. Charge carriers diffuse to recombine in the other piece of semiconductor. (b) The charge carriers recombine and a neutral depletion layer is formed. (c) The Fermi levels equalize, which has the effect of creating a potential slope. (d) In conventional Si-diode solar cells, the potential slope breaks the electron-hole pairs created by the absorption of photons. 


\subsection{Monocrystalline silicon solar cells}

Ordinary single-crystal silicon solar cells are made of a wafer of monocrystalline silicon, where the surface is diffused with p-type dopants, which turns the wafer into a thin $\mathrm{p}-\mathrm{n}$ junction. The wafer then acts as a large area photodiode. The absorbance of silicon is hampered by the fact that it is an indirect band gap semiconductor, which means that every time an electron is excited from the valence band to the conduction band a phonon (quantum of lattice vibration) must be produced. Involvement of the phonon makes the process more unlikely to occur. Due to the low absorbance and the brittleness of silicon, the silicon layer has to be relatively thick, about $300 \mu \mathrm{m}$ [7]. The thickness in turn means that some of the charge carriers have to travel long distances to be extracted by the front face. Consequently, a good material with high chemical purity and structural perfection is required to avoid the recombination of charge carriers. Such a monocrystalline silicon solar panel is depicted in Fig 4.

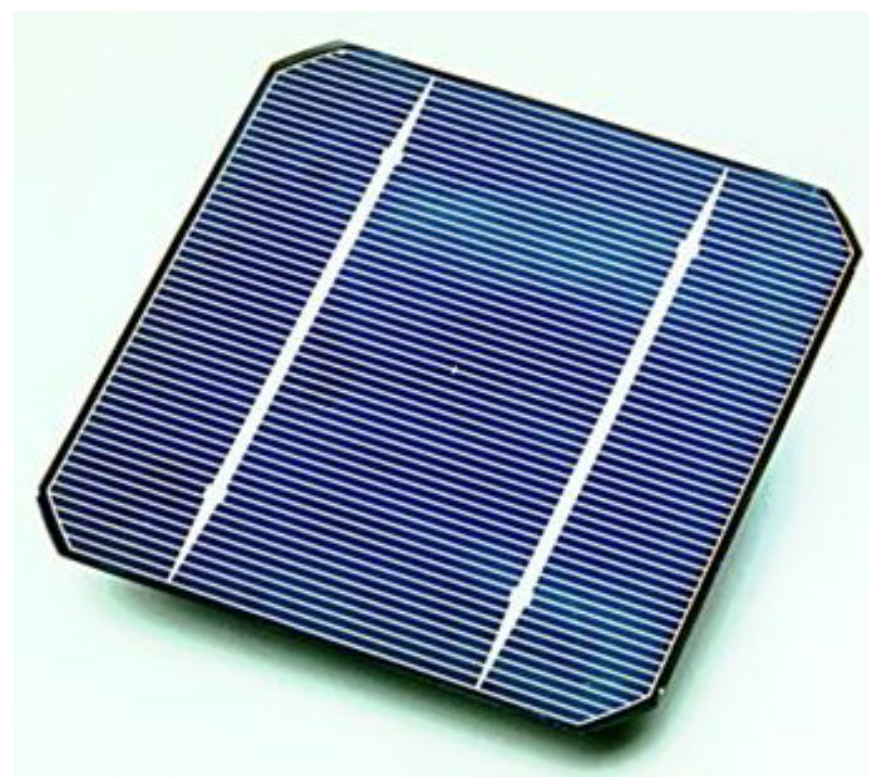

Figure 4: Solar cell made from a mono-silicon wafer [9].

\subsection{Tandem solar cells}

A tandem solar cell, also called a cascade or multi-junction cell, is a stack of normal monojunction solar cells with different band gaps and absorption spectra. It can achieve a higher total conversion efficiency by capturing a larger portion of the solar spectrum than a single solar-cell layer [7].

The individual cells are stacked on top of each other so that the layer with the highest band gap is on top and the one with the lowest is at the bottom. The 
photons absorbed first are the ones with the highest energy corresponding to the largest band gap of the topmost cell. The layer with a larger band gap than the energy of the incident photon is transparent to these lower-energy photons which continue on their way through the tandem solar cell until they get absorbed in the lower layers or leave the cell. This principle of operation is shown in Fig. 5.

The most efficient solar cells available are tandem solar cells. Unfortunately, they are also very expensive and are mostly used in mission-critical high-capital applications like satellites.

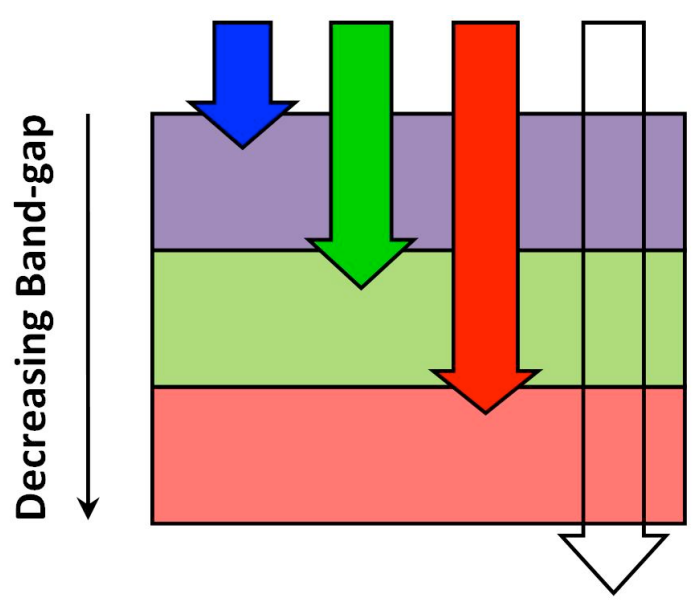

Figure 5: Principle of operation of a tandem solar cell: Multiple single-junction solar cells are stacked on top of each other with the highest band gap (blue) on top and the lowest (red) at the bottom.

\subsection{Dye-sensitized solar cells}

Dye-sensitized solar cells (DSSCs) are photoelectrochemical devices whose operating principle mimics the photosynthesis reaction of the green plants [10]. The advantages of this technology are numerous: simple manufacturing, relatively low cost, non-toxic and recyclable materials, and as a consequence of all this, suitability for wide variety of end-user products. DSSCs also work better with low light intensities than other solar-cell technologies. This enables their use in indoor applications. Their disadvantage is as yet their low efficiency of about 11\% (see figure 1) and chemical stability problems. This is countered to some extent by the fact that their low production costs lead to a good price/performance ratio. The number of kilowatt-hours produced for each invested dollar per installation square meter in one year $\left(\mathrm{kWh} / \mathrm{m}^{2} \cdot\right.$ annum $\cdot$ dollar $)$ is high.

The 2010 Millennium Technology Prize was awarded to Michael Grätzel for the invention of dye-sensitized solar cells [11]. 

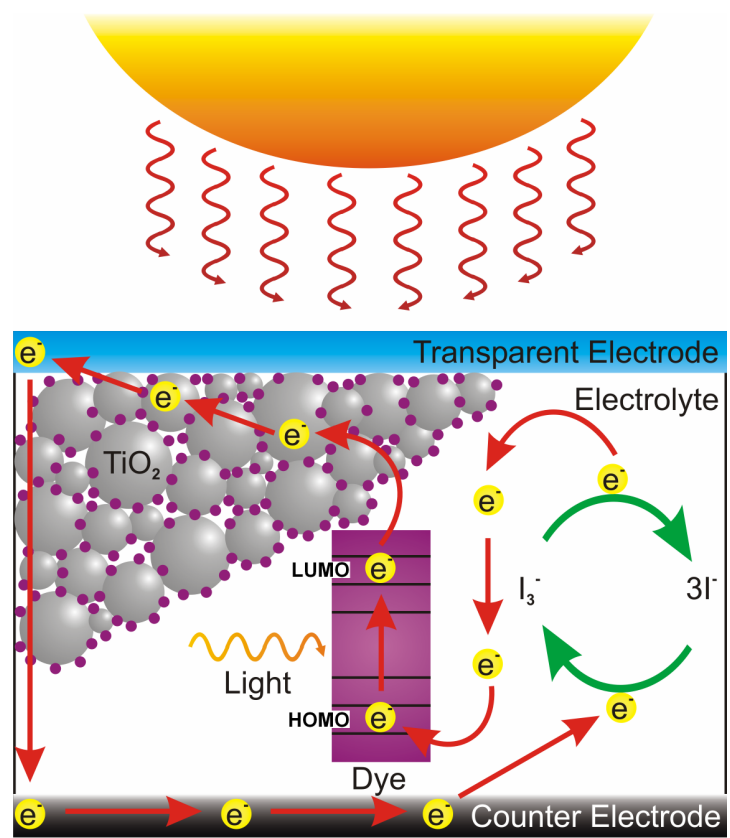

Figure 6: Structure and operating principle of the dye-sensitized solar cell (from Ref. [10]): Photon absorption induces a metal-to-ligand type electronic transition between the highest occupied molecular orbital (HOMO) and lowest unoccupied molecular orbital (LUMO) of the dye. Since the LUMO is located in the vicinity of the dye ligands (pyridyl $\pi$-orbitals) the electron injection to the $\mathrm{TiO}_{2}$ is spatially favorable.

\subsection{Hot carrier solar cells}

The efficiencies of standard silicon solar cells are limited to the $31 \%$ ShockleyQueisser efficiency, in part by the loss of all energy that exceeds the band gap energy. The surplus energy is transformed into heat. The developers of hot carrier solar cells try to inhibit the cooling of the photon and capture all of the energy the electron absorbs from the photon [12]. This would raise the theoretical efficiency limit to $66 \%$, which is the ultimate thermodynamic limit at one-sun solar concentration.

The cooling can be inhibited by augmenting the scattering among photoexcited electrons and the reabsorption of additional photons in the conduction band. Making scattering and reabsorption faster than cooling would lead to a quasiequilibrium characterized by an electron temperature much higher than the lattice temperature. The hot-carrier semiconductor would then be connected to an electron conductor in a narrow energy window to transfer the electrons further with minor energy loss.

A potential way to realize a hot carrier solar cell is to use semiconductor nanocrys- 
tals, i.e., quantum dots (QDs). When the charge carriers get trapped in these nanostructures, the quasi-continuous energy bands of the bulk semiconductor become discretized. Consequently, the energy spacing between the discretized energy levels can be much larger than the energy of the highest frequency phonons of the lattice, which creates a "phonon bottleneck". In the bottleneck the carrier relaxation is only possible by multiphonon emission, which is slower than singlephonon emission. This keeps the temperature of the photons high compared to the lattice temperature.

The research area of hot carrier solar cells is still very young and there are no functional devices yet. What has been demonstrated is that, the transfer of hot carriers from colloidal lead selenide (PbSe) nanocrystals to a titanium dioxide $\left(\mathrm{TiO}_{2}\right)$ electron acceptor is possible [13].

\subsection{Intermediate-band solar cells}

The idea of an intermediate-band solar cell (IBSC) is to introduce a half-filled intermediate electronic band into the solar-cell material. The intermediate band enhances the photogenerated current via the two-step absorption of sub-band-gap photons, see Fig. 7 for an illustration. The theoretical limiting efficiency of these cells is equivalent to that of a triple junction solar cell $(63.2 \%$ at maximum solar concentration). However IBSC requires only a single material instead [1].

Antonio Luque and Antonio Martí presented the idea of an IBSC in 1997 [1]. An experimental demonstration of the idea proved harder than expected, and it was not until 2006 when Martí et al. managed to show the production of photocurrent due to intermediate-to-conduction-band transitions [14]. The first actual IBSC was created in 2009 when Wang et al. realized a ZnTe:O IBSC with $100 \%$ increase in the short circuit current, $15 \%$ decrease in the open circuit voltage and overall $50 \%$ increase in the power conversion efficiency [2].

The band diagram of an IBSC as proposed by Luque and Martí[1] is shown in Fig. 9. The diagram contains the usual conduction band (CB) and valence band (VB) but, in addition, there is the intermediate band (IB). Such an intermediate band can be obtained by several means (lone pair bands, low-dimensional superlattices, impurities, etc.). The intermediate band can be introduced into the material, for example, by using a tight array of QDs. If the tunnelling probability of an electron from one dot to another is sufficiently large, effective electron bands are formed from the single-particle states of the QDs. This is depicted the Fig. 8. By changing the size of QDs, interdot distances, potential barrier height, and regimentation, one can control the electronic band structure of this so-called artificial crystal. 


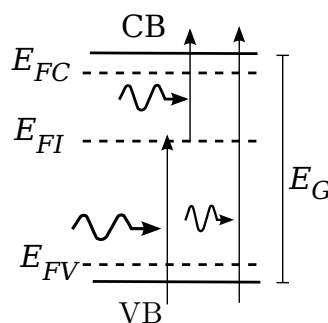

(a)

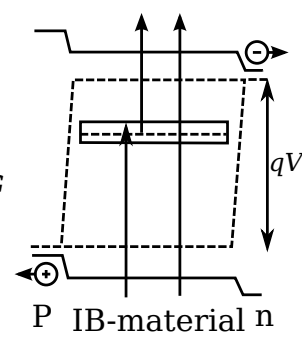

(b)

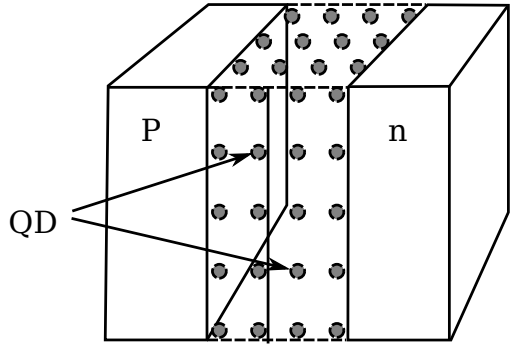

(c)

Figure 7: (a) Band structure of the intermediate-band (IB) solar cell (IBSC) concept. CB, IB and, VB represent the conduction, intermediate, and valence bands, respectively. $\mathrm{E}_{\mathrm{FC}}, \mathrm{E}_{\mathrm{FI}}$ and $\mathrm{E}_{\mathrm{FV}}$ are the quasi-Fermi levels of the electrons of the three different bands. (b) Basic structure of the IBSC: conventional $\mathrm{p}$ and $\mathrm{n}$ emitters with an IB-material layer in between. (c) Schematic structure of an IBSC where the IB is introduced into the material by quantum dots (from Ref. [15].

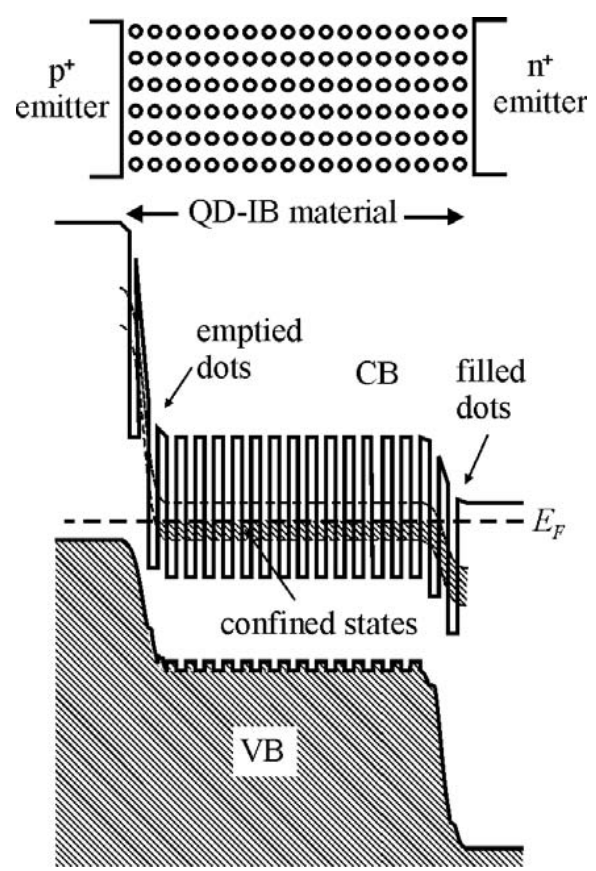

FIGURE 8: Illustration of intermediate band formation by means of a stacked array of quantum dots (from Ref. [16]). VB and CB denote the valence and conduction bands, respectively. 


\subsubsection{Efficiency of an ideal intermediate-band solar cell}

An ideal IBSC is defined as fulfilling the following conditions

1. Nonradiative transitions between any two of the three bands are forbidden.

2. Carrier mobilities are infinite, which leads to constant quasi-Fermi levels $\epsilon_{F C}, \epsilon_{F I}$, and $\epsilon_{F V}$ (see Fig. 9).

3. No carriers can be extracted from the intermediate band.

4. The cell is thick enough to assure full absorption of the photons with enough energy to induce any one of the electronic transitions $A_{C V}, A_{C I}$, or $A_{I V}$.

5. A perfect mirror must be located at the back of the cell so that the radiation generated in the cell by the processes $A_{C V}, A_{C I}$, and $A_{I V}$ can only escape by the front area of illumination.

6. For every range of energies $\left(\epsilon<\epsilon_{I}, \epsilon_{I}<\epsilon<\epsilon_{G}\right.$, and $\left.\epsilon_{G}<\epsilon\right)$ only one absorption length is important, so that a single Bose-Einstein function describes the population of photons escaping the cell in every mode.

7. Cell illumination is isotropic.

Because of these conditions the flux $\dot{N}$ of photons leaving the semiconductor is known, as the distributions are those of the thermodynamic equilibrium. Consequently, we find a relation

$$
\dot{N}\left(\epsilon_{m}, \epsilon_{M}, T, \mu\right)=\frac{2}{h^{3} c^{2}} \int_{\epsilon_{m}}^{\epsilon_{M}} \frac{\epsilon^{2} d \epsilon}{e^{(\epsilon-\mu) / k T}-1} .
$$

Here the temperature $T$ is the solar-cell temperature, which we take to be the ambient temperature $T_{a}=300 \mathrm{~K}$. The chemical potential $\mu$ depends on the energy range as follows:

$$
\mu=\left\{\begin{array}{lr}
\mu_{C V}=\epsilon_{F C}-\epsilon_{F V}, & \epsilon>\epsilon_{G} \\
\mu_{C I}=\epsilon_{F C}-\epsilon_{F I}, & \epsilon_{C}<\epsilon<\epsilon_{G} \\
\mu_{I V}=\epsilon_{F I}-\epsilon_{F V}, & \epsilon_{I}<\epsilon<\epsilon_{C}
\end{array}\right.
$$

Equation (1) for $\dot{N}$ can be used also for photons originating from the Sun. This is done by setting $T=T_{s}=6000 \mathrm{~K}$ and $\mu=0$. By doing so we assume the ideality condition 7 above. This assumption also implies that we use a concentrator with a geometrical concentration of at least 46000, which is the ratio of the Sun distance to its radius. This is the maximum concentration set by thermodynamic considerations [17].

By calculating the steady operation state balance of electrons at each band, the current $I$ provided by the device to an external load can be calculated. The current leaves the semiconductor by the valence band (positive contact) and returns by 


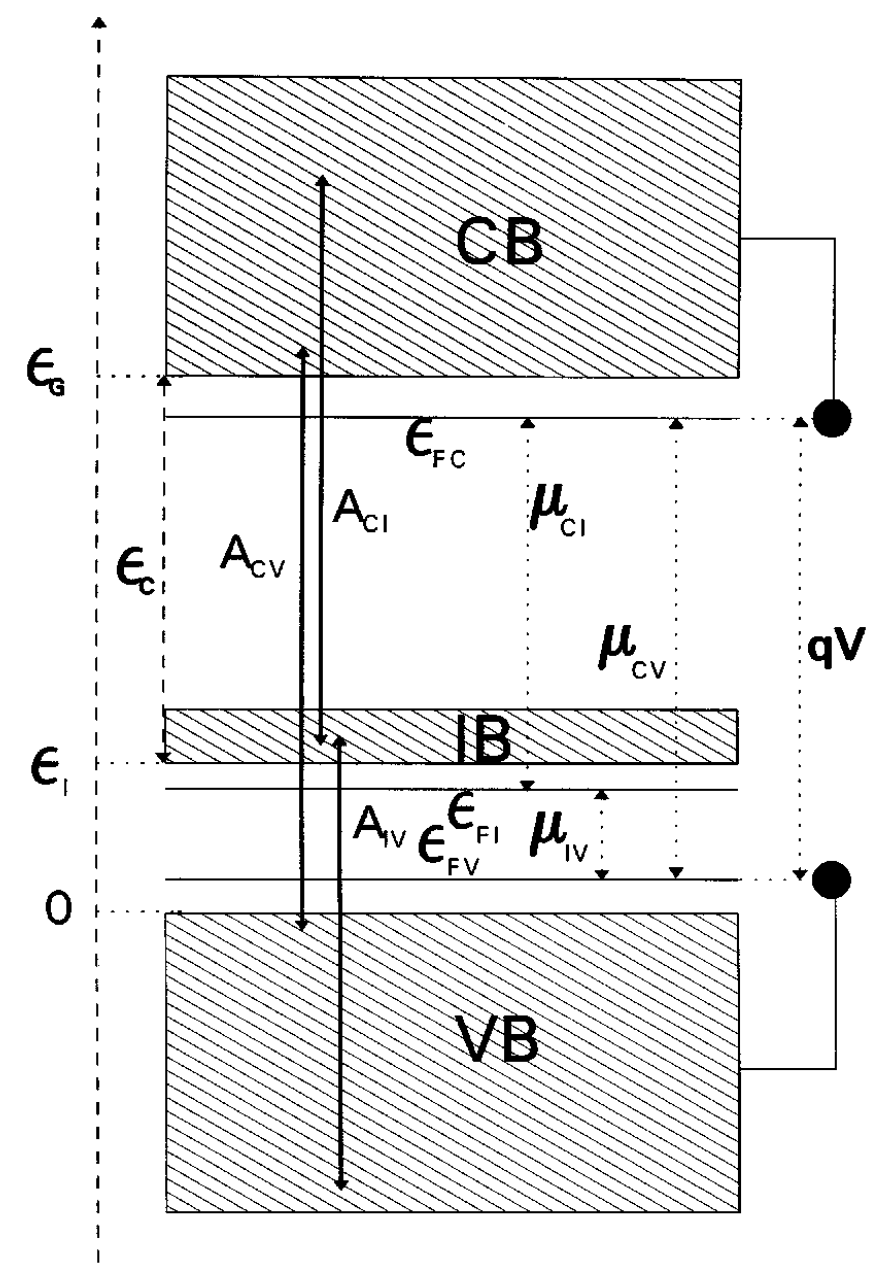

Figure 9: Simplified band diagram of an intermediate-band solar cell. CB, VB, and IB are the conduction band, valence band, and intermediate band, respectively. $\mu_{C V}, \mu_{C I}$, and $\mu_{I V}$ are the chemical potentials between the quasi-fermi levels $\epsilon_{F C}, \epsilon_{F I}$, and $\epsilon_{F V} \cdot C V, \mu_{C I}$, and $\mu_{I V}$. The electronic transition processes from a band to another are marked with $A_{C V}, A_{I V}$, and $A_{C I}$. 
the conduction band (negative contact). Thus, the current at the conduction band is

$I / q=\dot{N}\left(\epsilon_{G}, \infty, T_{s}, 0\right)-\dot{N}\left(\epsilon_{G}, \infty, T_{a}, \mu_{C V}\right)+\dot{N}\left(\epsilon_{C}, \epsilon_{G}, T_{s}, 0\right)-\dot{N}\left(\epsilon_{C}, \epsilon_{G}, T_{a}, \mu_{C I}\right)$

As no current is extracted from the intermediate band (ideality condition 3), the latter two terms can be written as

$$
\dot{N}\left(\epsilon_{I}, \epsilon_{G}, T_{s}, 0\right)-\dot{N}\left(\epsilon_{I}, \epsilon_{C}, T_{a}, \mu_{I V}\right)=\dot{N}\left(\epsilon_{C}, \epsilon_{G}, T_{s}, 0\right)-\dot{N}\left(\epsilon_{C}, \epsilon_{G}, T_{a}, \mu_{C I}\right) .
$$

Since the chemical potentials equal the output voltage (see Fig. 9), i.e.,

$$
q V=\mu_{C I}+\mu_{I V}=\mu_{C V},
$$

we can solve the efficiency for any pair $\left\{\epsilon_{I}, \epsilon_{G}\right\}$ within the following procedure:

1. Choose arbitrary values for $\epsilon_{I}$ and $\epsilon_{G}$.

2. For every voltage $V=\mu_{C V}$

I. Solve from Eq. (3) the corresponding $\mu_{I V}$ and $\mu_{C I}$.

II. Calculate the current $I$ from Eq. (2).

III. Power output is now given by Joule's law $P=I V$. If this is the maximum power thus far for this pair $\left\{\epsilon_{I}, \epsilon_{G}\right\}$, retain it.

3. Divide the maximum power output with the power delivered by the Sun on the cell area taking into account the use of a solar concentrator.

In Sec. 8 we demonstrate the use of this algorithm to obtain the maximum efficiency of a chalcopyrite IBSC. 


\section{Quantum dots}

Low-dimensional nanometer-sized systems have come into the spotlight of science as the semiconductor processing and manufacturing techniques have refined during the last 30 years. The refined techniques allow creating fermionic nanostructures with just a few confined electrons. These artificial atoms or quantum dots (QDs), as they are also called, present researchers new exciting physics and technological applications in, e.g., quantum information processing [18].

Restricting an electron along a dimension leads to the quantization of energy levels along that direction. This can be clearly seen from the density of states (DOS) curve of a quasi-two-dimensional structure depicted in Fig.10 where a staircase-like form of the DOS results from the quantization in one direction and the energy continuum of the other two dimensions. Quasi-dimensionality means in this context that the box length tends to zero in one or two dimensions. This is different from strict low-dimensionality because the existense of the confined dimension still presents a certain degree of freedom which leads to discrete energy levels in the confined dimensions.

The electronic structure of QDs is in general a complicated topic. There are many factors affecting the electronic structure such as the materials, electronic and magnetic fields, geometry of the dot and its surroudings, defects, doping, etc. We restrain ourselves to include in the calculations only the major contributing factors, i.e., the confining potential, the geometry of the dot arrangement, the effective mass of the charge carrier, and the dielectric constant of the material.

\subsection{Applications in intermediate-band solar cells}

One may implement the intermediate band in the solar-cell matrix material by constructing QDs into the matrix material [15]. In this approach, a superlattice consisting of QDs made of a reduced band gap material is embedded in a semiconducting matrix with a larger band gap. The offsets of the conduction (electrons) or the valence (holes) band, together with the quantum confinement provided by the QDs, give rise to a region with finite density of states within the matrix band gap.

A rough approximation for the minimum diameter ensuring at least one bound state in a spherical QD, is given by

$$
D_{\min }=\frac{\pi \hbar}{\sqrt{2 m^{*} \Delta E_{\mathrm{b}}}},
$$

where $m^{*}$ is the effective mass of the carrier to be confined and $\Delta E_{\mathrm{b}}$ is the energy barrier between the dot and the matrix, i.e., the valence band offset (electrons) or the conduction band offset (holes). 

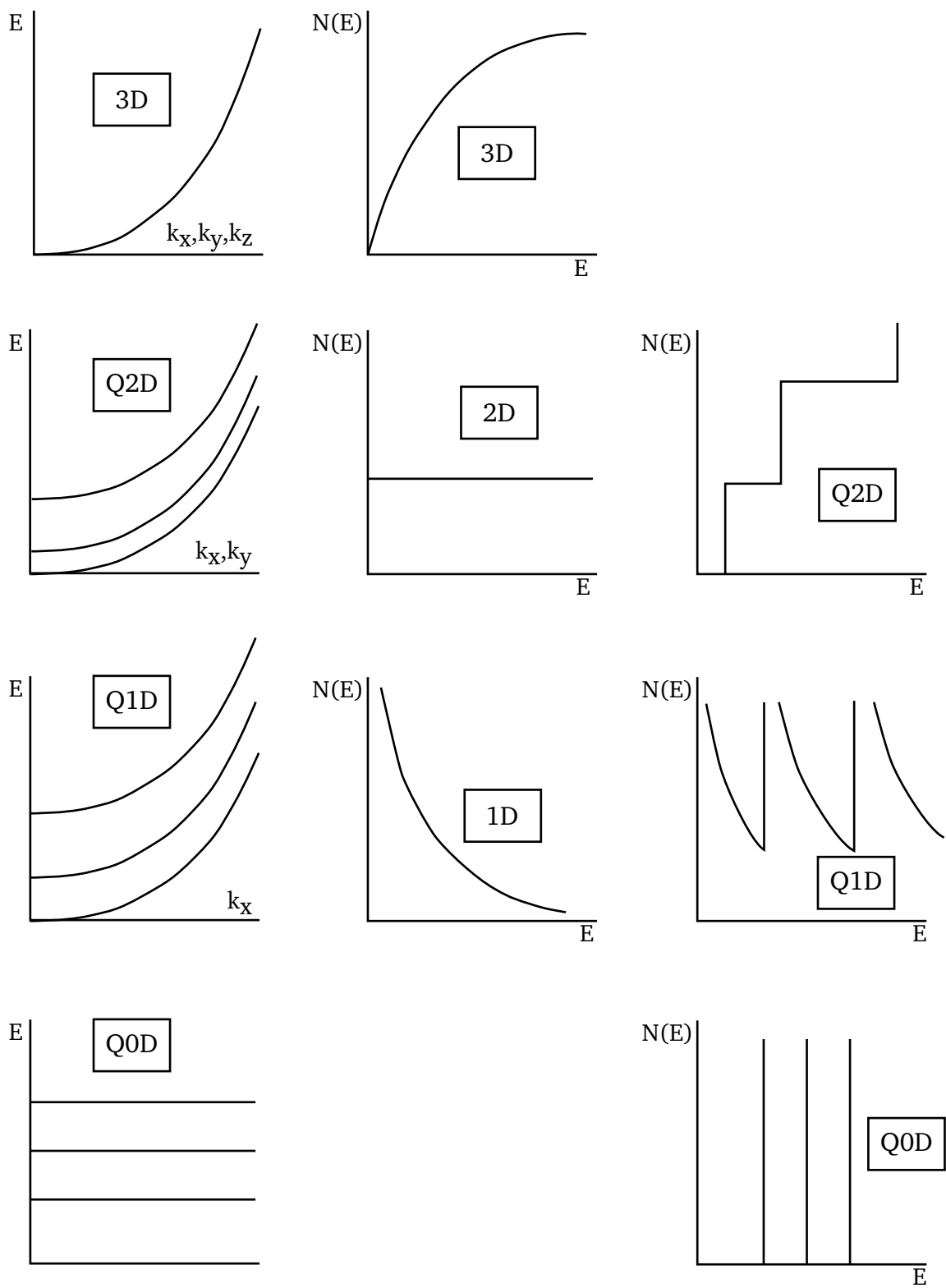

Figure 10: (a) Energy bands and (b) densities of states in various dimensions and quasi-dimensions for an electron in a box (from Ref. [19]). 
The maximum size of the QD is derived from the requirement that the thermal population of the excited states should be small. If we require less than $5 \%$ occupation at room temperature $(300 \mathrm{~K})$ we must have the level separation

$$
k T \leq \frac{1}{3}\left(E_{1}-E_{0}\right)
$$

where $E_{0}$ and $E_{1}$ are the energies of the first and second energy level of the QD, respectively. For a $3 \mathrm{D}$ spherical $\mathrm{QD}$ we have $E_{1}-E_{0}=2 E_{0} / 3=2 \hbar \omega / 3$, where $\omega$ is the harmonic oscillator strength which can be deduced from the size of the QD.

\subsection{Chalcopyrite quantum dots}

Chalcopyrite $\mathrm{Cu}(\mathrm{In} / \mathrm{Ga})(\mathrm{S} / \mathrm{Se})_{2}$ offers a very promising material for solar-cell applications. Chalcopyrite-based solar cells already lead the efficiency ranking of thin-film technologies (see Fig. 1). The efficiency is due to the high absorbance of chalcopyrite which is a direct gap semiconductor. As discussed in Sec. 5.1, a direct gap allows better absorbance and efficiency.

Chalcopyrite crystal belongs to the tetragonal scalenohedral point group $\overline{4} 2 \mathrm{~m}$ in Hermann-Mauguin notation [20]. This configuration, as seen in Fig. 11, is very similar to those of diamond and wurtzite crystal structures but has three different elements as opposed to two in wurtzite and one in diamond crystal structure.

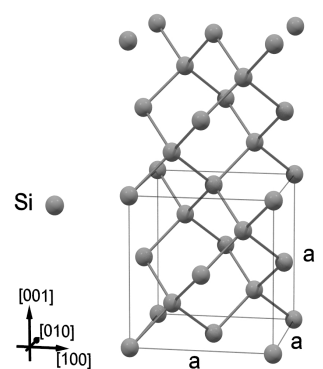

(a)

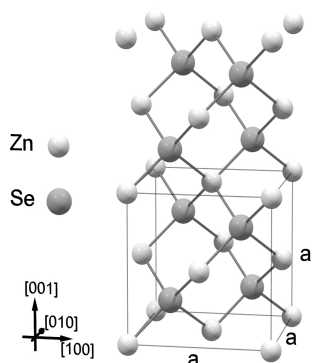

(b)

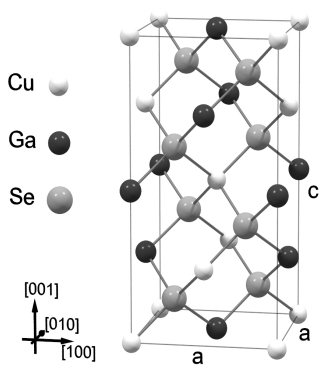

(c)

Figure 11: Unit cells of three similar crystals: (a) Diamond structure, (b) zinkblendestructure, and (C) chalcopyrite-structure (from Ref. []); Also shown are the lattice constants a and $\mathrm{c}$.

A chalcopyrite layer can be grown in various ways. The structural, optical and electrical properties of chalcopyrite are adjustable by modifying the growth conditions and composition. The material also allows band gap engineering by changing the contents of the different element groups III and VI. The band gap can be as 


\begin{tabular}{llll}
\hline compound & carrier & eff. mass $\left(m_{0}\right)$ & $D_{\max }(\mathrm{nm})$ \\
\hline \multirow{2}{*}{$\mathrm{CuGaS}_{2}$} & electron & 0.13 & 10.6 \\
& hole & 0.69 & 4.6 \\
$\mathrm{CuGaSe}_{2}$ & electron & 0.14 & 10.2 \\
& hole & 1.2 & 3.5 \\
$\mathrm{CuInS}_{2}$ & electron & 0.16 & 9.5 \\
& hole & 1.3 & 3.3 \\
$\mathrm{CuInSe}_{2}$ & electron & 0.09 & 12.7 \\
& hole & 0.79 & 4.3 \\
\hline
\end{tabular}

TABLE 1: Estimated maximum size $D_{\max }$ of chalcopyrite nanostructures containing $\mathrm{Cu}$, within the effective-mass approximation [22].

low as $0.95 \mathrm{eV}\left(\mathrm{CuInSe}_{2}\right)$ or as high as $3.0 \mathrm{eV}\left(\mathrm{CuGaS}_{2}\right.$ with $\mathrm{Al}$ doping) [21]. The band gaps of the chalcopyrite system are also easily modifiable by altering the composition. Together with the high efficiency of ordinary thin-film chalcopyrite solar cells, this suggests that chalcopyrite has potential in QD-IBSC applications [22]. The idea is to form a superlattice consisting of QDs with a reduced band gap embedded in a chalcopyrite matrix with a larger band gap.

An estimation for the maximum size of chalcopyrite QDs can be derived from the requirement of Eq. (6). The maximum sizes for chalcopyrite compounds $\mathrm{Cu}(\mathrm{In} / \mathrm{Ga})(\mathrm{S} / \mathrm{Se})_{2}$ are shown in the table 1 .

Figure 12 shows the calculated minimum dimension of the QDs as a function of the energy barrier $\Delta E_{\mathrm{b}}$ [see Eq. (5)]. Vertical lines in the figure indicate optimal values for the position of the IB in the respective chalcopyrite hosts. Due to different effective masses of electrons and holes, the minimum size of QDs leading to confinement depends on the carrier type considered.

\subsubsection{Tetrahedral chalcopyrite nanostructures}

Dr. Sascha Sadewasser's group in Helmholtz Zentrum, Berlin, has used molecular beam epitaxy (MBE) to grow chalcopyrite solar cell samples. They have imaged the samples using scanning tunnelling microscope which allows for the surface topography to be observed. This has revealed the tetrahedral chalcopyrite nanostructures formed on the surface of the silicon substrate. The distinctive shape is a result of the self-organizing tendency of chalcopyrite: on the surface of silicon the energetically preferred structure for chalcopyrite is the tetrahedron. An example of the structure is shown in Fig. 13. Further analysis of the tetrahedra has shown that they are very close in shape to an ideal tetrahedron [23]. 


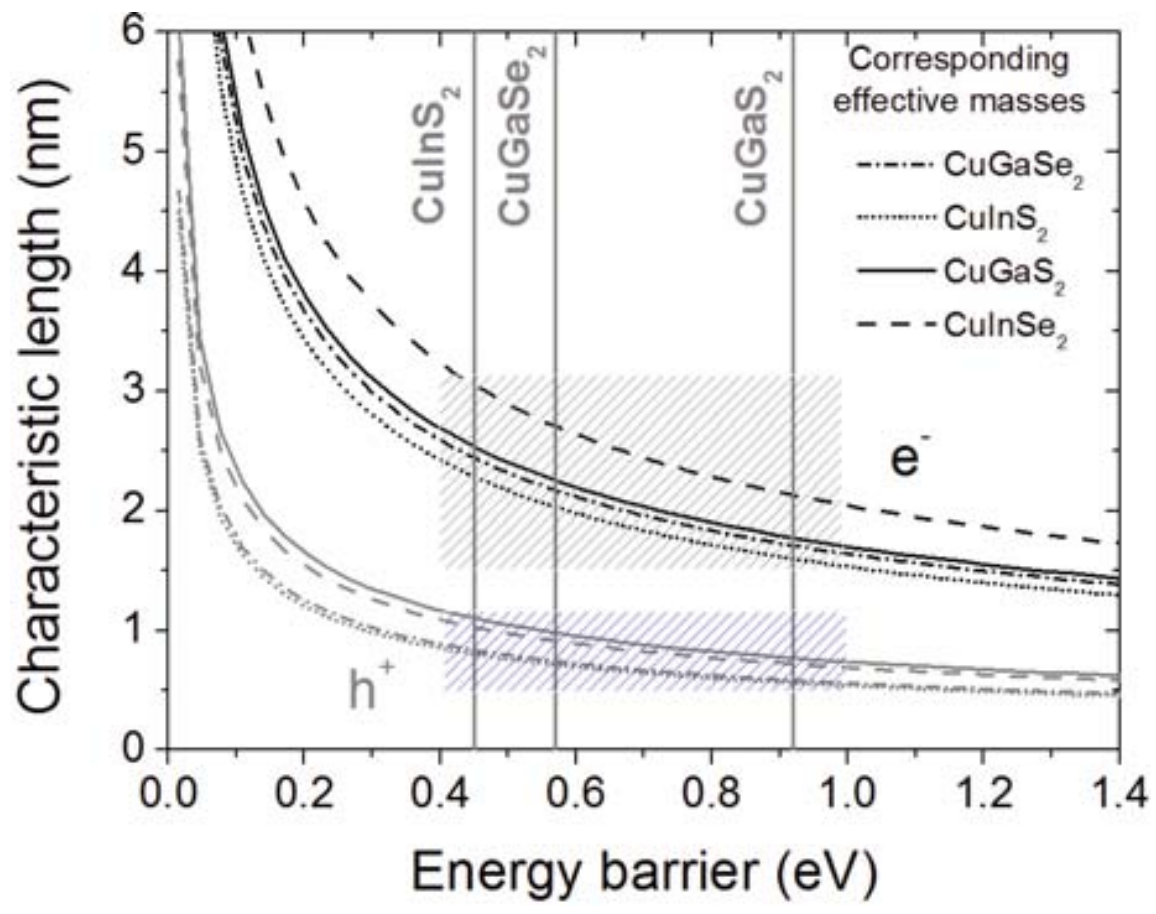

FigURE 12: Minimum required characteristic length of nanostructures leading to carrier confinement calculated for holes and electrons as a function of the energy barrier. Gray lines represent dimensions for hole-like bound states and black lines for electron-like bound states. Effective carrier masses of the respective chalcopyrite compounds are given in Table 1. Vertical lines indicate optimal values of energy barriers for intermediate-bands in the respective chalcopyrite hosts.

Given some refinement in regimentation and size distribution, the type of tetrahedra shown in Fig. 13 could be used as tetrahedral chalcopyrite quantum dots in a chalcopyrite thin-film QD-IBSC. The samples produced thus far serve as a proof-of-concept. In the future lithographic techniques will be used to obtain better control of size, form and placement of the nanostructures. 


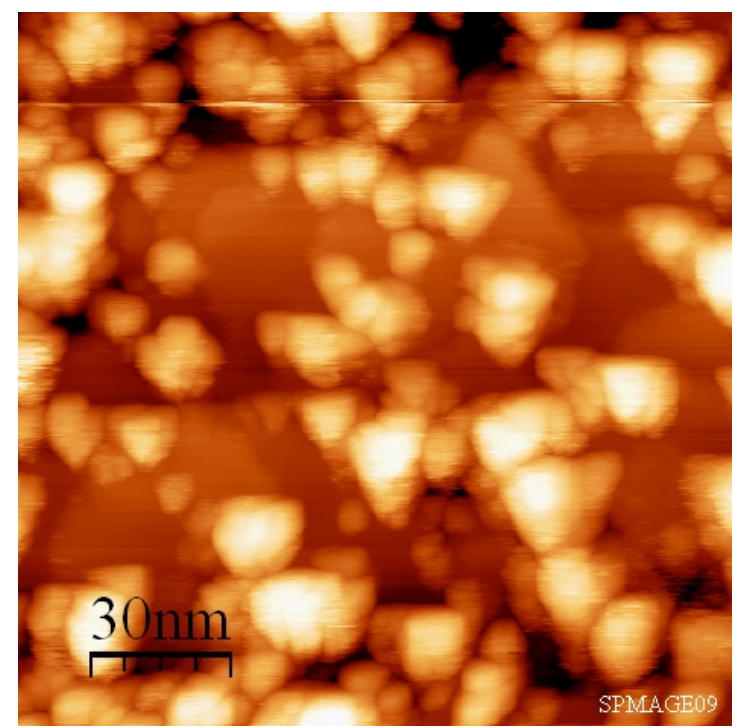

0.0
$12.6 \mathrm{~nm}$

(a)

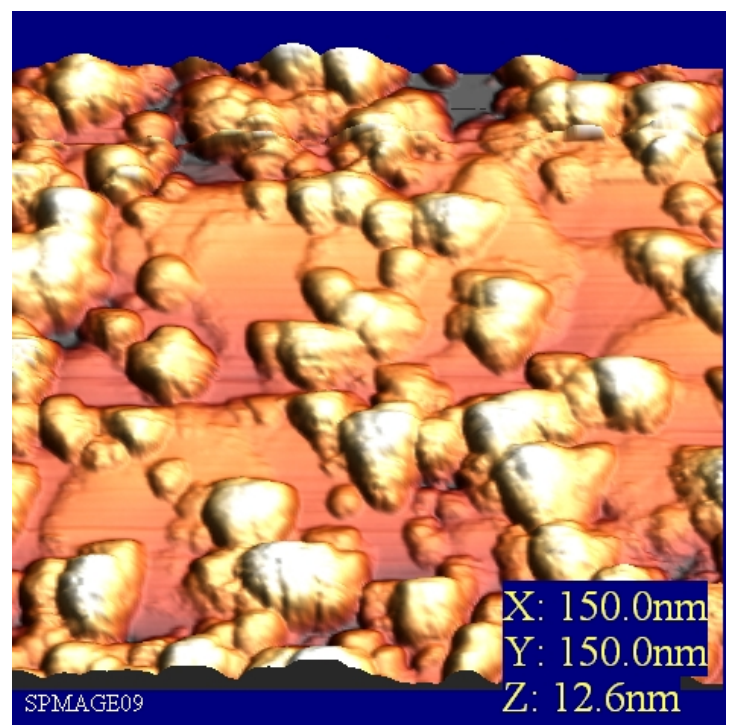

(b)

Figure 13: (a) Scanning tunneling microscope image of a sample of $\mathrm{CuGaSe}_{2}$ tetrahedral nanostructures on Si substrate. (b) Three dimensional depiction of the same data. Figures from [23]. 


\section{Theoretical methods}

Since the problem of solving the Schrödinger equation is present in any quantum mechanical calculation in some form, many computational techniques have been developed. Some of the most common techniques are perturbation theory, the Hartree-Fock method, exact diagonalization, quantum Monte Carlo methods, and density-functional theory (DFT) [24]. In the calculations of this thesis DFT is employed with the effective mass approximation for the structures studied.

\subsection{Effective mass approximation}

There are two main ways to calculate the electronic structure of a QD. One is to take the whole semiconductor structure and the substrate into the calculation. This is the so-called atomistic approach. Unfortunately, this is computationally very demanding or unfeasible in any computational scheme since hundreds of atoms in a complex layer structure would have to be taken into account.

The other route is to calculate the behavior of just a few conduction-band electrons of the QD device and treat the ions and surroundings with a model potential $V_{\text {ext }}(\mathbf{r})$, that depends on the geometry, defects and the construction technique of the QD. The electrons are assumed to be near the band minimum where the band can approximated as parabolic. Their electron mass can thus be replaced by the effective mass which is defined as

$$
m^{*}=\hbar^{2} \cdot\left[\frac{d^{2} \epsilon}{d k^{2}}\right]^{-1}
$$

for an isotropic material.

The lower lying electrons are thus treated as screening. This demands that we also take into account the dielectric constant $\epsilon$ of the dot material. Given a sufficiently deep QD potential well, we can assume that the wavefunctions do not penetrate deep into the matrix material, and we can ignore the dielectric constant of the matrix and just use the same dielectric constant throughout.

The model Hamiltonian in the effective mass approximation becomes (in SI units)

$$
\hat{\mathrm{H}}=\sum_{i=1}^{N}\left[-\frac{\hbar^{2}}{2 m^{*}} \nabla_{i}^{2}+V_{\mathrm{ext}}\left(\mathbf{r}_{i}\right)\right]+\frac{e^{2}}{4 \pi \epsilon_{0} \epsilon} \sum_{i<j}^{N} \frac{1}{\left|\mathbf{r}_{i}-\mathbf{r}_{j}\right|},
$$

where the first term is the kinetic energy of the electrons, the second is the model potential of the QD and the third is the Coulomb interaction between the electrons. Typical values for the effective mass and the dielectric constant for a GaAs QD are $m^{*}=0.067 m_{e}$ and $\epsilon \approx 13$ [18]. 
The effective mass approximation is a rather drastic approximation and it has a few drawbacks. For example, the space dependence of the effective mass and the dielectric constant in heterostructures can lead to non-parabolicity of the energy bands near $k=0$ [25]. However, the effective mass approximation has been widely used to calculate the electronic structure of QDs with success [18].

\subsection{Density-functional theory}

Density-functional theory (DFT) is a reformulation of many-body quantum mechanics in terms of the electron density. DFT is widely used to investigate the ground-state properties of atoms, molecules, and solid state devices, such as QDs. Generally, the ground-state problem is solved through the many-body Schrödinger equation

$$
\hat{\mathrm{H}} \Psi\left(\mathbf{r}_{1}, \mathbf{r}_{2}, \ldots, \mathbf{r}_{N}\right)=\mathrm{E} \Psi\left(\mathbf{r}_{1}, \mathbf{r}_{2}, \ldots, \mathbf{r}_{N}\right),
$$

where $\hat{H}$ is the many-body Hamiltonian of the system described by $\Psi$, and $E$ is the ground-state energy. DFT reduces the $N$-particle $3 N$-dimensional problem expressed in the true many-body wavefunction $\Psi\left(\mathbf{r}_{1}, \mathbf{r}_{2}, \ldots, \mathbf{r}_{N}\right)$ into a 3-dimensional problem expressed with the electron density $n(\mathbf{r})$ alone.

The pioneering work on DFT was done by Hohenberg and Kohn (HK) when they published in 1964 two theorems which gave DFT a firm theoretical footing [26].

Hohenberg-Kohn theorem 1. For any system of interacting particles there exists a one-to-one mapping between the ground state density $n_{G S}(r)$ and the external potential $V_{\text {ext }}(r)$.

The first HK theorem has the consequence that the ground state energy $E_{G S}$ and all other expectation values of the system are unique functionals of the ground state electron density $n_{G S}(r)$.

Hohenberg-Kohn theorem 2. The functional $E[n]$ for the ground state energy is minimized by the ground state electron density $n_{G S}$. In other words, $E[n] \geq$ $E\left[n_{G S}\right]$ for every trial electron density $n$ and $E_{G S}=E\left[n_{G S}\right]$.

The second HK theorem is a direct consequence of the first theorem and the Rayleigh-Ritz variational principle.

In practice, DFT is most commonly applied within the Kohn-Sham (KS) scheme [27], where we have an auxiliary non-interacting system with its own set of noninteracting wavefunctions $\psi_{i}(\mathbf{r}, \sigma)$. In addition to the normalization requirement $\sum_{\sigma} \int d \mathbf{r}\left|\psi_{i}(\mathbf{r}, \sigma)\right|^{2}=1$, the KS orbitals must satisfy the condition that the squared norms sum exactly to the total electron density

$$
n(\mathbf{r})=\sum_{i}^{N}\left|\psi_{i}(\mathbf{r})\right|^{2} .
$$


In the KS system the KS potential is defined as

$$
v_{\mathrm{KS}}[n](\mathbf{r})=v_{\mathrm{ext}}[n](\mathbf{r})+v_{\mathrm{H}}[n](\mathbf{r})+v_{\mathrm{xc}}[n](\mathbf{r}),
$$

where $v_{\text {ext }}$ is the external potential describing, e.g., the nuclei in a molecule or a model confining potential for a $\mathrm{QD}, v_{\mathrm{H}}$ is the classical electron-electron repulsion, i.e., the Hartree potential, and the last one is the villain of the story, the exchangecorrelation potential $v_{\mathrm{xc}}$ which in most cases has to approximated.

The KS orbitals $\psi_{i}$ are solved from an (effective) single-particle Schrödinger equation

$$
\left[-\frac{\hbar^{2}}{2 m} \nabla_{i}^{2}+v_{\mathrm{KS}}(\mathbf{r})\right] \psi_{i}(\mathbf{r})=\epsilon_{i} \psi_{i}(\mathbf{r})
$$

The KS equations (10), (11) and (12) have to be solved self-consistently. This leads to an iterative scheme illustrated in Fig. 14. At every iteration, when one obtains a new electron density (or a new KS potential), one has to mix it with that of the previous iteration in order to obtain convergence.

After solving the KS equations, which yields the ground state density $n(\mathbf{r})$, the total energy of the system can be obtained from

$$
E=\sum_{i}\left[\epsilon_{i}-\left\langle\psi_{i}\left|v_{\mathrm{H}}+v_{\mathrm{xc}}\right| \psi_{i}\right\rangle\right]+E_{\mathrm{xc}}
$$

where the exchange-correlation potential $v_{\mathrm{xc}}$ is defined as the functional derivative of the exchange-correlation energy $E_{\mathrm{xc}}$ with respect to the density

$$
v_{\mathrm{xc}}(\mathbf{r})=\frac{\delta E_{\mathrm{xc}}[n(\mathbf{r})]}{\delta n(\mathbf{r})}
$$

The eigenenergies $\epsilon_{i}$ of the KS orbitals $\psi_{i}$ were long assumed to have no direct physical meaning apart from that of the highest occupied molecular orbit corresponding to the ionization potential. From theoretical considerations stemming from time-dependent DFT, one can see that they are zeroth-order approximations to the optical excitation energies [28].

\subsubsection{Exchange and correlation}

Knowing the exact exchange-correlation potential $v_{\mathrm{xc}}$ and energy $E_{\mathrm{xc}}$ would lead to the exact ground-state density and total energy of the system. In practice, however, the exchange-correlation terms need to be approximated. Fortunately, there exists many sufficiently accurate and computationally inexpensive approximations for these terms. 


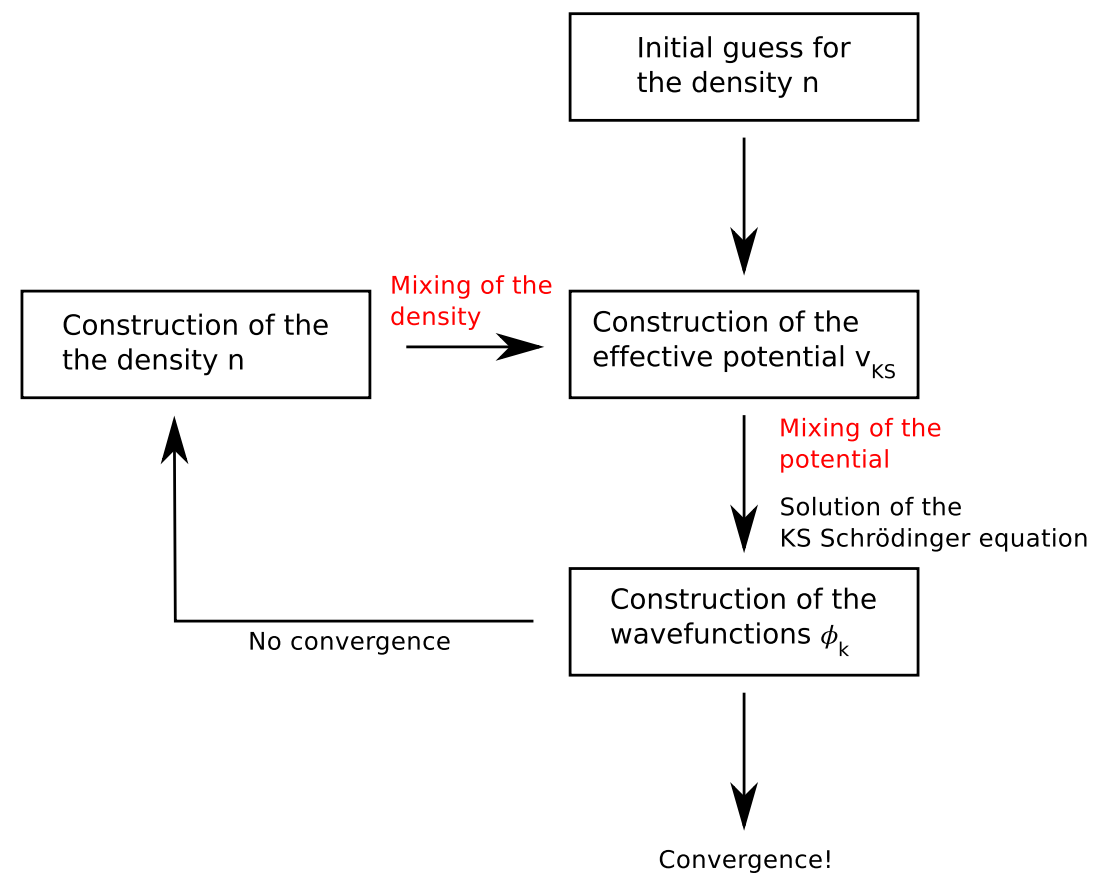

FIGURE 14: Self-consistent iteration cycle used in density-functional theory. Here the convergence test is placed in the wave function construction step but it could as well be tested in the density construction step. Mixing (in red) is done either for the density or for the potential.

One of the simplest and the most widely used approximations for $v_{x c}$ and $E_{x c}$ is the local-density approximation (LDA) in which the exchange-correlation energy operator $v_{x c}$ is approximated to only depend on the local density $n(\vec{r})$. The energy density $\epsilon_{x c}[n(\vec{r})]$ corresponding to different densities is taken from the results for the homogenous electron gas for which there exists an analytic expression for the exchange and parametrized results from quantum Monte Carlo simulations for the correlation part. LDA can be expressed as

$$
E_{x c}^{\mathrm{LDA}}[n]=\int n(\mathbf{r}) \epsilon_{x c}^{\mathrm{HEG}}(n) \mathrm{d} \mathbf{r}
$$

for the exchange-correlation energy and

$$
v_{x c}^{\mathrm{LDA}}(\mathbf{r})=\frac{\delta E_{x c}^{\mathrm{LDA}}}{\delta n(\mathbf{r})}=\epsilon_{x c}^{\mathrm{HEG}}(n(\mathbf{r}))+n(\mathbf{r}) \frac{\partial \epsilon_{x c}^{\mathrm{HEG}}(n(\mathbf{r}))}{\partial n(\mathbf{r})}
$$

for the exchange-correlation potential. Here HEG refers to the homogenous electron gas.

LDA is exact for a uniform electron gas and quite accurate for solids, but has gives less than satisfactory results for several atoms and molecules. Fortunately, more 
advanced and accurate exchange-correlation functionals have been derived [29]. These exchange-correlation functionals can be ordered in the order of complexity and accuracy in the so-called "Jacob's ladder" [30]. The lowest three rungs of this ladder, in the ascending order, are: (i) LDA; (ii) generalized gradient approximations (GGA), which are functionals of not only the density $n$ but also the gradient of density $\nabla n$; (iii) meta-GGAs that also make use of the kinetic energy density and/or the Laplacian of the density $\nabla^{2} n$. Even higher in the ladder lie the orbital functionals that depend explicitly on the KS orbitals. For example, the exact exchange energy $E_{x}^{\text {exact }}$ can be derived leading to the exact exchange (EXX) formalism. Now the corresponding exchange potential can be evaluated indirectly through the so-called optimized effective potential (OEP) method.

Mixing exact and approximate exchange functionals gives rise to hybrid functionals. It is also common in quantum chemistry to construct hybrids in an empirical or semi-empirical manner.

\subsection{Time-dependent density functional theory}

Time-dependent DFT (TDDFT) is an extension of DFT to calculate not only static ground state properties but also the many-particle properties of timeevolving systems. By applying TDDFT one can calculate the effect of timedependent electronic and magnetic fields, excitation energies, photoabsorption spectra, and much more [28].

The cornerstone for TDDFT was laid by Runge and Gross in 1984 when they proved a theorem that is today known as the Runge-Gross theorem [31]. It states that the external time-dependent potential has a one-to-one correspondence with the time-dependent density. Analogously to DFT, equations linking the external potential $v_{\text {ext }}$, the density $n$, and the action $A[\rho]$ can be derived. In TDDFT the action

$$
A[\rho(\mathbf{r})]=\int d t\langle\psi(t)|i \partial-\hat{H}(t)| \psi(t)\rangle
$$

is a unique functional of the density $n$, like the total energy is in static DFT. The extrema of the action $A$ give the exact density, i.e.,

$$
\frac{\delta A[n]}{\delta n(r, t)}=0
$$

again analogously to DFT where extrema of the total energy $E$ give the exact density.

The challenge of coming up with an accurate and numerically efficient exchangecorrelation functional for the ground state DFT is imposing. Now, with the timedependence it is even harder because the exchange-correlation potential $v_{x c}(\mathbf{r}, t)$ 
is not a function of only the instantaneous density $n(\mathbf{r}, t)$ but of all the previous densities as well.

The simplest solution is called adiabatic LDA (ALDA) which is just the normal LDA with no time-dependence added in. The adiabaticity refers to an assumption that that the density changes so slowly that the change has only a very small effect on $v_{\mathrm{xc}}$ and we can neglect the possible "memory" effects.

\subsection{Optical response from linear-response}

The linear-response function is the first coefficient of the Taylor expansion of the density in terms of the electric field $\vec{E}$,

$$
\chi_{i j}^{(1)}(\omega)=\delta \rho(\omega) / E_{j}(\omega)=\alpha_{i j}(\omega) .
$$

The relation of this quantity to the photo-absorption cross section $\sigma(\omega)$, of which we actually are interested in, is

$$
\bar{\alpha}(\omega)=\frac{1}{3} \operatorname{Tr}[\alpha(\omega)] \propto \frac{\sigma(\omega)}{\omega} .
$$

\subsubsection{Casida formalism}

Mark Casida published the first practical formulation of linear-response theory in the TDDFT formalism [32]. He showed that the dynamical dipole polarizability $\alpha(\omega)$ has the sum-over-states expression

$$
\alpha_{i j}(\omega)=\sum_{I} \frac{2\left(E_{I}-E_{0}\right)\left\langle\psi_{0}|\hat{i}| \psi_{I}\right\rangle^{2}\left\langle\psi_{I}|\hat{j}| \psi_{0}\right\rangle^{2}}{\left(E_{I}-E_{0}\right)^{2}-\omega^{2}},
$$

where $\psi_{0}$ is the ground-state wavefunction, $\psi_{I}$ is the excitation wavefunction, $E_{0}$ and $E_{I}$ are the corresponding energies, and $\hat{i}, \hat{j} \in\{\hat{x}, \hat{y}, \hat{z}\}$ are the dipole moment operators. This expression has the interesting feature that the spectroscopic oscillator strengths,

$$
F_{I}=\frac{2}{3}\left(E_{I}-E_{0}\right)\left(\left\langle\psi_{0}|\hat{x}| \psi_{I}\right\rangle^{2}+\left\langle\psi_{0}|\hat{y}| \psi_{I}\right\rangle^{2}+\left\langle\psi_{0}|\hat{z}| \psi_{I}\right\rangle^{2}\right)
$$

and the excitation energies,

$$
\omega_{I}=E_{I}-E_{0}
$$

are the poles and residues of the mean polarizability,

$$
\bar{\alpha}(\omega)=\sum_{I} \frac{f_{I}}{\omega_{I}^{2}-\omega} .
$$


For adiabatic exchange-correlation kernels the squares of the excitation energies $\omega_{I}$ are all the eigenvalues of a specific matrix equation

$$
\mathbf{Q F}_{\mathrm{I}}=\omega_{I}^{2} \mathbf{F}_{\mathrm{I}}
$$

where

$$
Q_{i j \sigma, k l \tau}=\delta_{i k} \delta_{j l} \delta_{\sigma \tau} \epsilon_{i j \sigma}^{2}+2 \sqrt{\epsilon_{i j \sigma} \epsilon_{k l \tau}} K_{i j \sigma, k l \tau},
$$

where $\epsilon_{i j \sigma}$ is the energy difference between $i$ :th and $j$ :th single-particle states with spin $\sigma . \mathbf{K}$ in equation (26) is the coupling matrix

$$
K_{i j, k l}(\omega)=\iint \psi_{i}^{*}(\mathbf{r}) \psi_{j}^{*}(\mathbf{r})\left(\frac{1}{\left|\mathbf{r}-\mathbf{r}^{\prime}\right|}+f_{x c}\left(\mathbf{r}, \mathbf{r}^{\prime}, \omega\right)\right) \psi_{k}\left(\mathbf{r}^{\prime}\right) d \mathbf{r} d \mathbf{r}^{\prime}
$$

\subsubsection{Sternheimer formalism}

Sternheimer perturbation theory is an earlier formalism for calculation of the linear-response [33]. In the Sternheimer approach the KS wavefunctions $\psi_{i}$ are perturbed by a monochromatic field and then expanded in the powers of the magnitude of the perturbing field. A first order variation $\delta \hat{H}$ to the KS Hamiltonian $\hat{H}$ is considered. After some algebra, one obtains the Sternheimer eigenvalue equation

$$
\left\{\hat{H}-\epsilon_{m} \pm \omega+i \mu\right\} \delta \psi_{m}(\mathbf{r}, \pm \omega)=-P_{c} \delta \hat{H}( \pm \omega) \psi_{m}(\mathbf{r})
$$

In equation (28) $P_{c}$ is the projector onto the unoccupied subspace and $\mu$ a positive infinitesimal, essential to obtain the imaginary part of the polarizability.

\subsection{Optical response from direct time-evolution}

The optical response can be obtained also from the time-evolution of the system by perturbing it with an external potential $V(\vec{r}, t)=\kappa \delta(t)$ and then evolving in time by applying the time-evolution operator

$$
\hat{U}(t)=\exp \left[-\frac{i}{\hbar} \int_{0}^{t} H\left(t^{\prime}\right) d t^{\prime}\right]
$$

on the KS states obtained from a ground-state calculation. The optical properties can then be obtained from the Fourier transform of the resulting total dipole moment

$$
\mathbf{P}(t)=\int n(\mathbf{r}, t) \mathbf{r} d \mathbf{r}
$$


The main advantage of this approach is that the time-evolution method scales and parallelizes much better than the eigenvalue problem of the Casida technique. The Casida approach also requires the calculation of a large number of unoccupied states. Numerical and theoretical aspects of the time-evolution method and Sternheimer linear response are considered in detail in the doctoral thesis of Xavier Andrade [33].

\subsection{Numerical methods}

There exists many different (TD)DFT codes aimed at different purposes and with different numerical methods. Octopus, which was chosen for this thesis, is a versatile DFT code which allows one to do virtual experiments on a wide range of static and time-dependent systems [34]. Most importantly, it is well suited for $\mathrm{QD}$ calculations since it has user-definable external potentials in real-space representation, the dimensionality $(1 \mathrm{D}, 2 \mathrm{D}, 3 \mathrm{D})$ can be freely chose, and different kinds of periodic calculations are possible.

Octopus can be used to calculate the linear optical response of molecules and clusters, the non-linear response to classical high-intensity electromagnetic fields, ground-state and excited state electronic properties of low-dimensional systems (QDs, quantum wires, etc.), photo-induced reactions of molecules, and optimal control of quantum systems. In addition, Octopus provides a large number of different exchange-correlation functionals through libXC, some of which are designed for low-dimensional systems, increasing its applicability to QDs. Unlike many other DFT codes Octopus does not use a basis set, but relies on bare regular numerical meshes.

Octopus is free software published under the GPL license and as such relatively easily extended. It is mostly written in clear and well-structured Fortran 90 with some auxiliary parts written in C or Perl. Standard GNU tools have been used, and Octopus is rather easily compiled on any Unix-like platform.

\subsubsection{Computational details}

Octopus was used for all calculations presented in this thesis.

In the ground-state calculation the iteration was continued until the relative density change was less than $10^{-5}$. This guarantees an accuracy of $<1 \mathrm{meV}$ if other calculation parameters are well set (see below).

The grid spacing in all calculations was $L / 70$ which was the maximum for computers with $2 \mathrm{~GB}$ of working memory. Here $L$ is the QD radius. This corresponds to about 1400000 grid points altogether. In the ground-state calculations, the 
calculation sphere radius was varied between $4 L$ and $10 L$. In the linear-response calculations 50 unoccupied states were calculated in addition to the states in the first two electronic shells. The exchange-correlation functional was LDA in all calculations that had many-particle interactions included. 


\section{Results}

We will concentrate on two different material combinations suggested for sample fabrication at the Helmholtz Zentrum in Berlin:

- ZnSe-matrix/CuGaSe $\mathrm{Cu}_{2}$-dots

- $\mathrm{CuGaSe}_{2}$-matrix/CuInSe ${ }_{2}$-dots

The band alignments of the material combinations ZnSe-matrix/CuGaSe ${ }_{2}$-dots and $\mathrm{CuGaSe}_{2}$-matrix/CuInSe ${ }_{2}$-dots are presented in Fig. 15. The QD well depth is $V_{0}=0.77 \mathrm{eV}$ for holes in the ZnSe-matrix $/ \mathrm{CuGaSe}_{2}$-dots system and $V_{0}=1.18 \mathrm{eV}$ for electrons in the $\mathrm{CuGaSe}_{2}$-matrix/CuInSe ${ }_{2}$-dots system. The values correspond to the valence and conduction band offsets, respectively.

Due to the lack of experimental information about the band alingment of the $\mathrm{CuGaS}_{2} / \mathrm{CuInSe}_{2}$ heterojunction, this heterojunction is approximated with the transitivity rule via $\mathrm{CuGaSe}_{2}$. This approximation might not be that good since the lattice constants of $\mathrm{CuGaS}_{2}$ and $\mathrm{CuInSe}_{2}$ are 10.1216 a.u. and 10.9303 a.u., respectively [35]. The $8 \%$ deviation in the lattice constants is significant and creates strain in the heterojunction, which might change the heterojunction band alignment.

The $\mathrm{ZnSe} / \mathrm{CuGaSe}_{2}$ system would be positively doped and uses holes as charge carriers. Holes have an effective mass of $1.2 m_{0}$ in the dot material $\mathrm{CuGaSe}_{2}$ (cf. Table 1). The $\mathrm{CuGaSe}_{2} / \mathrm{CuInSe} \mathrm{C}_{2}$ system would be negatively doped and the charge carriers would be electrons that have an effective mass of $0.09 \mathrm{~m}_{0}$ in the $\mathrm{CuInSe}_{2}$ dots.

In the calculations, the effective mass of the charge carrier is chosen to be the one in the dot material. If the effective mass of the charge carrier is much different in the matrix material, we can expect that as we increase the penetration of the QD electron density to the matrix the accuracy of the calculations suffers. This can occur if we bring several QDs in a multiple periodic QD configuration closer to each other so that delocalized states form.

Fortunately, in our case, the effective masses of dot and matrix materials are rather close to each other. $\mathrm{ZnSe} / \mathrm{CuGaSe}_{2}$ system has hole masses $1.26 m_{0} / 1.2 m_{0}$ and the $\mathrm{CuGaSe}_{2} / \mathrm{CuInSe}_{2}$ system has electron masses $0.14 m_{0} / 0.09 m_{0}$ (see Table 1 and Ref. [36]). The quoted value for the mass of the hole in ZnSe is the heavyhole mass. The heavy hole band has a higher density of states than the light-hole band and thus has dominant effect on the physics of the QD. 

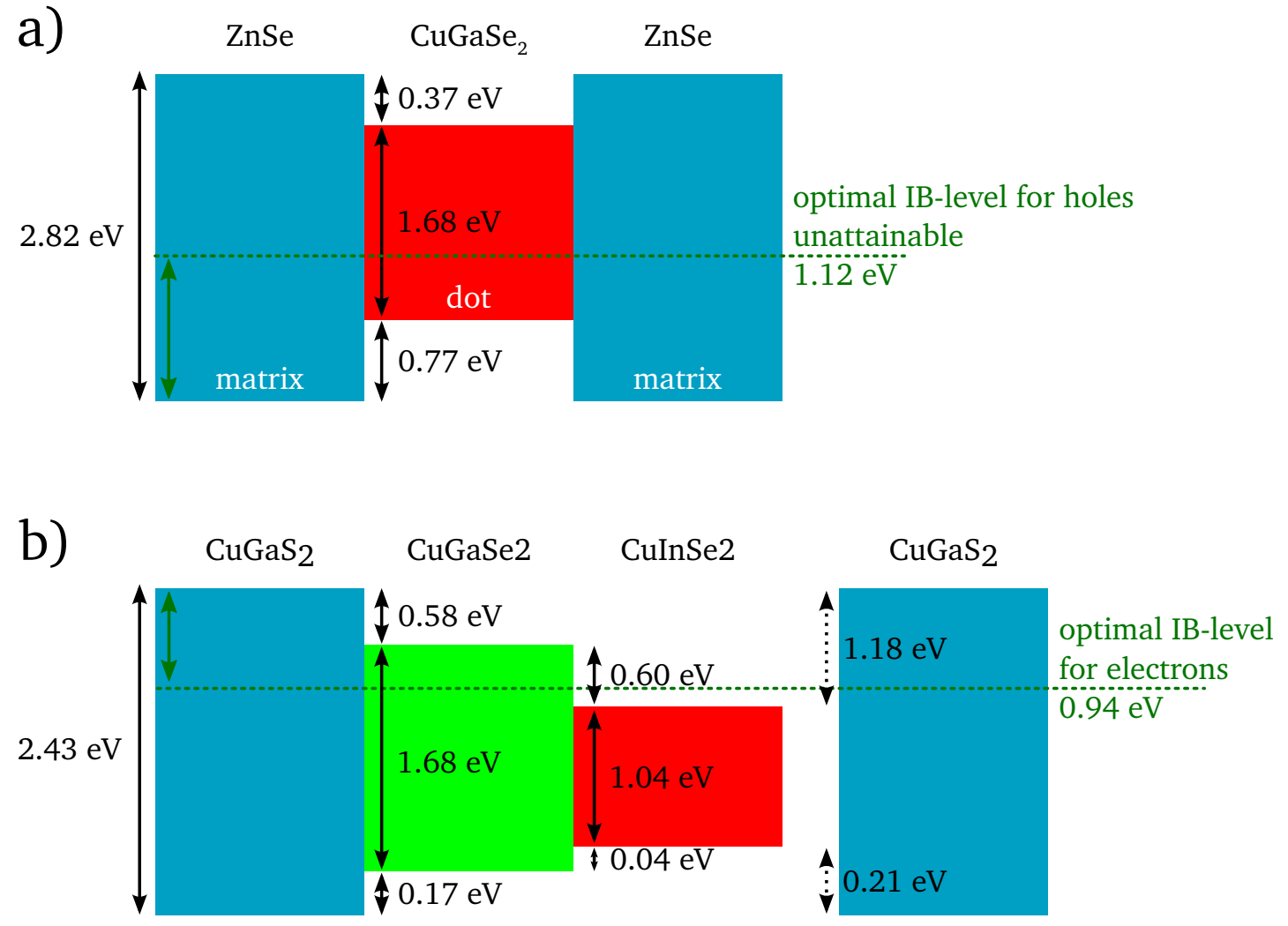

Figure 15: Band offsets for a) ZnSe-matrix/CuGaSe ${ }_{2}$-dots and b) $\mathrm{CuGaS}_{2^{-}}$ matrix/CuInSe $e_{2}$-dots material combinations at $0 \mathrm{~K}$. No direct information was available at the time of writing about the second system, so it is here approximated via $\mathrm{CuGaSe}_{2}$. 


\subsection{Optimal efficiency}

Using the procedure described in detail in Sec. 5.5.1 we can plot the efficiency of an IBSC as a function of the band gap $\epsilon_{g}$ and the intermediate band position $\epsilon_{i}$ (see Fig. 16). From Fig. 16 one can read the optimal band alignment for the suggested matrix materials. For an IBSC implemented in $\mathrm{CuGaS}_{2}\left(\epsilon_{g}=2.43 \mathrm{eV}\right)$ we should have $\epsilon_{i}=1.12 \mathrm{eV}$ and in $\mathrm{ZnSe}\left(\epsilon_{g}=2.82 \mathrm{eV}\right)$ we should have $\epsilon_{i}=$ $0.94 \mathrm{eV}$ in order to obtain the maximum theoretical efficiency. These positions correspond to efficiencies of $61.1 \%$ and $57.3 \%$, respectively.

The overall best combination of band gaps is $\left(\epsilon_{g}, \epsilon_{i}\right)=(1.97 \mathrm{eV}, 0.72 \mathrm{eV})$. For this band gap combination we obtain an impressing theoretical maximum efficiency: $63.17 \%$.

\subsection{Realistic model}

In QD calculations a harmonic potential is the standard model for the confinement of the electrons. In our case of tetrahedral chalcopyrite QDs it does not apply too well. The harmonic potential does not have a finite depth and it does not correspond to the shape of the dot (tetrahedron). This is why we consider a tetrahedral gaussian model potential defined by the equation

$$
V_{\mathrm{ext}}(\mathbf{r})=-V_{0} \exp \left[-\left(\mathbf{r} \cdot \mathbf{n}_{i}\right)^{2} / 2 L^{2}\right]
$$

where $L$ is taken as the radius of the QD and $\mathbf{n}_{i}$ is the normal vector of the face the vector $\mathbf{r}$ points to. The model potential is depicted in the Fig. 17. The softness of the Gaussian potential enables us to model the slowly varying confining potential, which results from the nonabrupt interface between the QD and matrix regions [37].

The Gaussian potential possesses the finite depth and range and - in the vicinity of the dot center - it can be approximated by a parabolic potential

$$
\tilde{V}_{\text {ext }}(\mathbf{r})=-V_{0}+\gamma^{2} L^{2}
$$

where $\gamma^{2}=V_{0} / 2 R^{2}$ (cf. Fig 18). A comparison between the single-particle energy levels of spherical Gaussian and harmonic potential wells is shown in Fig. 18. The QD potential well depth $V_{0}$ is approximated to be equal to the valence (conduction) band offset between the dot and matrix materials when the charge carriers are electrons (holes). 


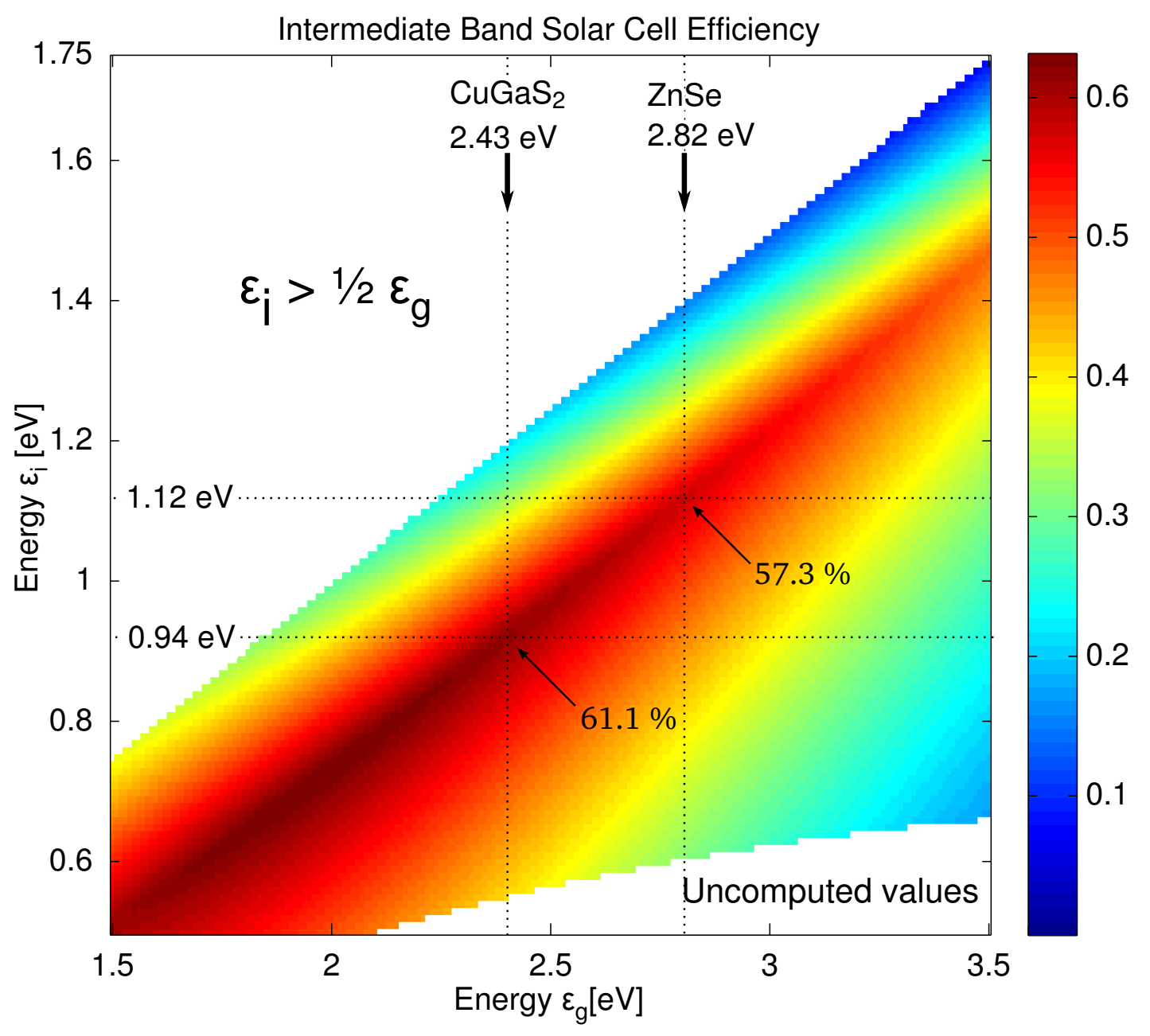

Figure 16: Efficiency of an intermediate-band solar cell as a function of the band gap $\epsilon_{g}$ of the matrix material and the intermediate band position $\epsilon_{i}$. Band gaps of $\mathrm{CuGaS}_{2}$ and ZnSe matrix materials and the corresponding optimal intermediate band positions are marked in the figure. Because of symmetry, points for which $\epsilon_{i}>1 / 2 \cdot \epsilon_{g}$ are omitted. 


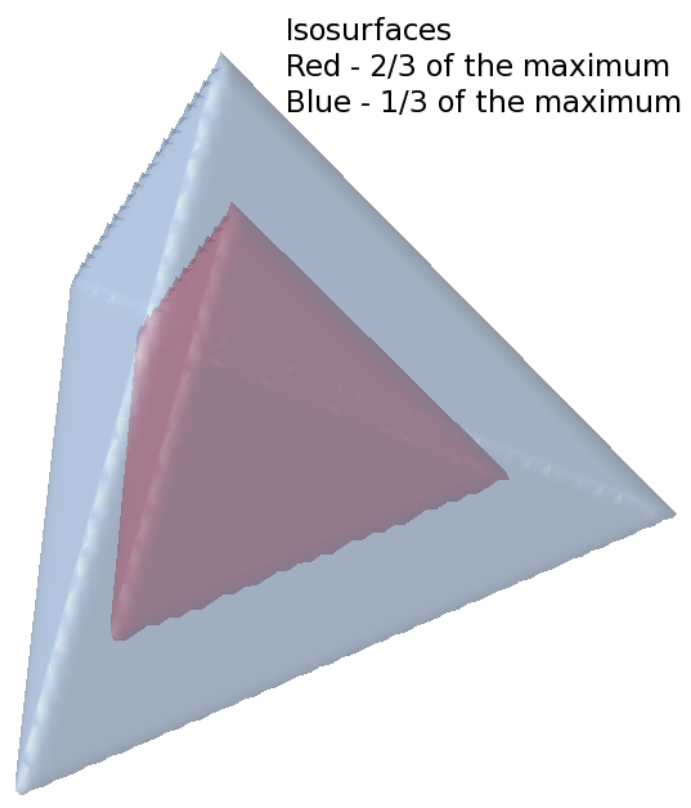

Figure 17: Two equipotential surfaces of the gaussian tetrahedral model potential.

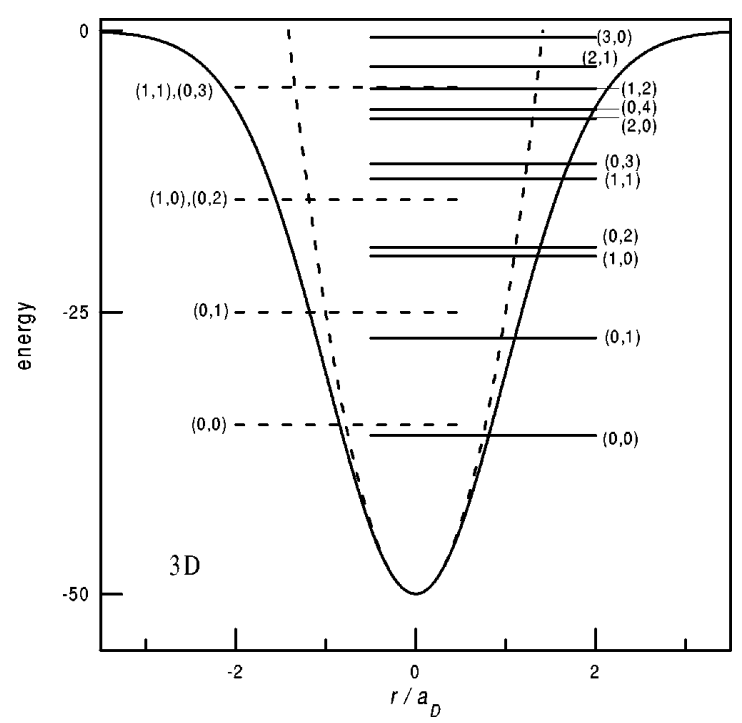

FiguRE 18: a) One-electron energy levels for the spherical Gaussian (solid lines) and harmonic (dashed lines) three-dimensional potential wells with $V=50 R_{D}=$ $50\left(m_{e}^{*} V_{0} / 2 \epsilon^{2} R\right)$ and $R=a_{D}=\epsilon a_{\text {bohr }} / m_{e}^{*}$ (Ref. [37]). The energy levels are labelled by the quantum numbers $(\mathrm{n}, \mathrm{J})$. The energy scale is in $R_{D}$ and the position scale in $a_{D}$. 


\subsection{Size optimization}

As described in Sec. 8.1 a major factor in the efficiency of a QD-IBSC is the placement of the half-filled intermediate band, i.e., the ground state of an electron in the QD. For this reason, we first optimize the placement of this band, i.e, the energy of the first electron state for our two material combinations.

\subsubsection{ZnSe/CuGaSe 2}

The optimal intermediate band placement $\epsilon_{i}=1.12$ (see fig. 16) is unattainable for the $\mathrm{ZnSe} / \mathrm{CuGaSe}_{2}$ combination due to the shallow valence band offset (see fig. 15), but it is still possible to find the maximum size of the QD with regard to the thermal occupation of Eq. (6). Figure 19 shows the energies of the lowest two single-particle states as a function of QD size. The energies are measured from the valence band. The maximum size is $1.69 \mathrm{~nm}$ with an IB placement of $E_{0}=632 \mathrm{eV}$ from the valence band of ZnSe. From Fig. 16 we can read that this very much unoptimal value still corresponds to a maximum theoretical efficiency of $32.5 \%$.

\subsection{2 $\mathrm{CuGaSe}_{2} / \mathrm{CuInSe}_{2}$}

For this material combination we can achieve the optimal intermediate band placement $\epsilon_{i}=0.94$. The single-particle energies of the lowest two states of the QD are plotted as a function of the QD size in Fig. 20. The optimal IB position corresponds to a $4.43 \mathrm{~nm}$ QD (see Fig. 20). The ground-state energy level of the dot corresponds now to the optimal IB position $940 \mathrm{meV}$ below the conduction band edge. This placement gives the very impressive theoretical maximum efficiency of $61.1 \%$ (see Fig. 16). The first excited state of the dot remains thermally separated from the ground state as the energy difference is much larger than the constraint set by Eq. (6). 


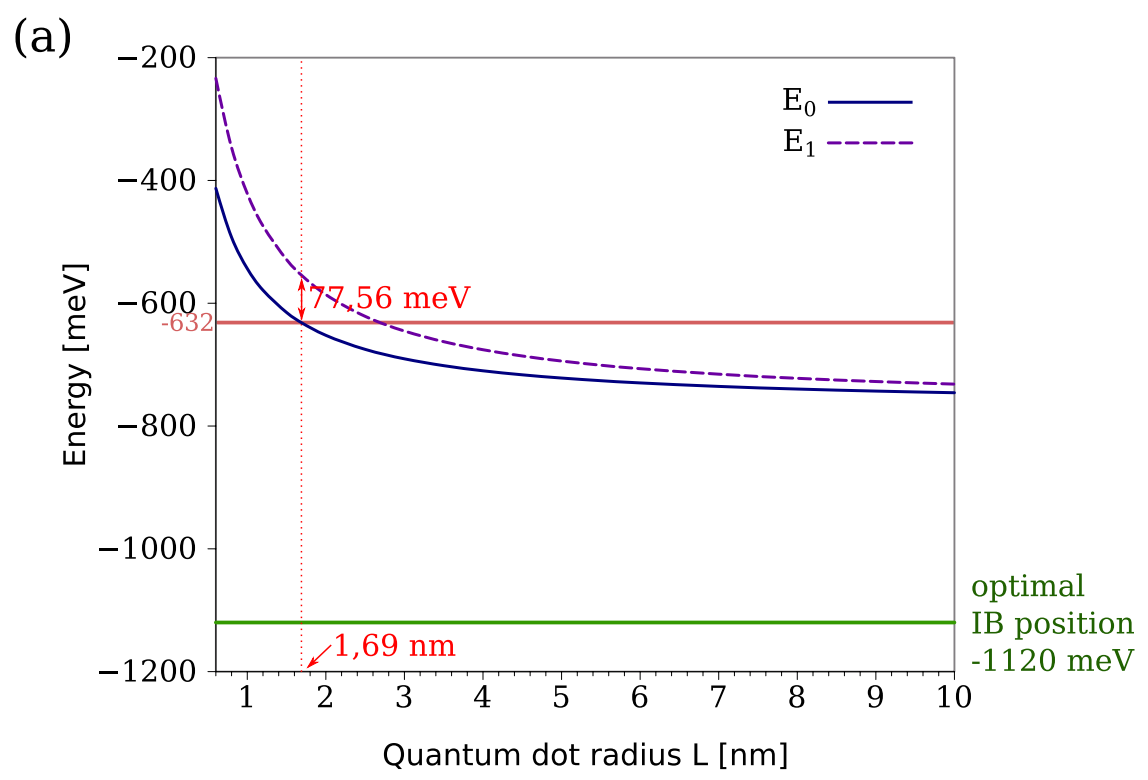

(b)

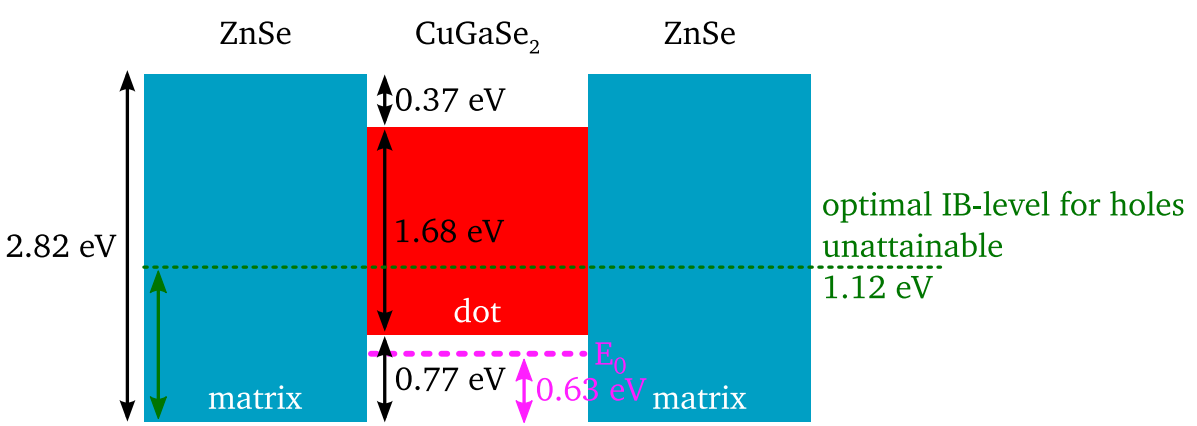

Figure 19: (a) Difference between the first and second single-electron states of a tetrahedral quantum dot in the $\mathrm{ZnSe} / \mathrm{CuGaSe}_{2}$ material combination. For this material system the band alignment is unattainable, but we can calculate the maximum size (giving the highest intermediate band and the best efficiency) for which the constraint of Eq. (6) holds. The maximum size is $L=1.69 \mathrm{~nm}$ which corresponds to $E_{0}=-632 \mathrm{meV}$ when the QD depth is the valence band offset $-770 \mathrm{meV}$. (b) Same as Fig. 15 but with the first single particle state energy, when QD size is $L=1.69 \mathrm{~nm}$, marked in violet on the figure. 


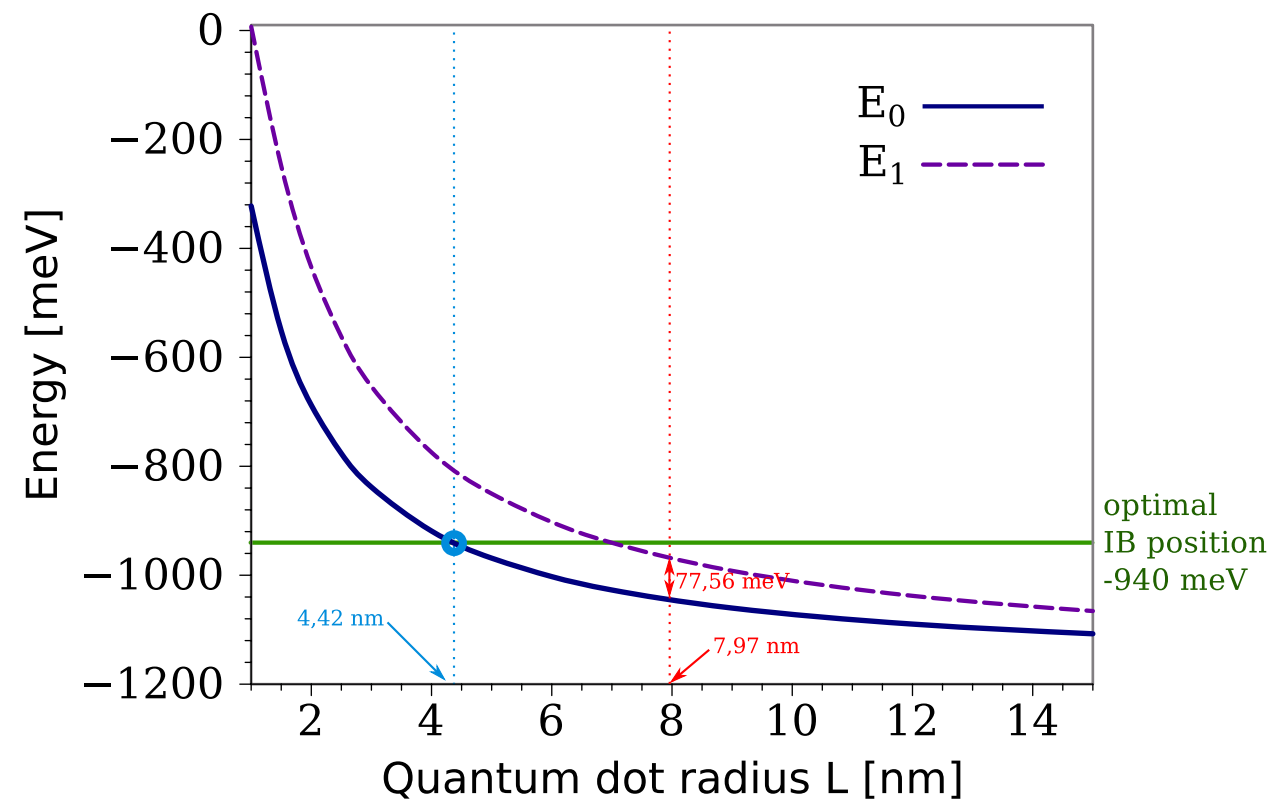

Figure 20: Energies of the first and second electronic states of a $\mathrm{CuInSe}_{2}$ dot in $\mathrm{CuGaS}_{2}$ matrix as a function of the quantum dot radius. For the $\mathrm{CuGaS}_{2} / \mathrm{CuInSe} 2$ material combination the optimal intermediate band position is attainable with quantum dot radius $L=4.43 \mathrm{~nm}$. The well depth with this radius is $1.18 \mathrm{eV}$. The number in red marks the maximum size of the QD w.r.t. the constraint of Eq. (6). 


\subsection{Geometric effects of the chalcopyrite dot}

In the STM images (cf. Fig 13) the shape of the tetrahedral nanostructures seems rounded. Some of the apparent roundness is likely due to the roundness of the STM tip since in the TEM images the shape of the nanostructures look very close to an ideal tetrahedron [23]. In order to analyze the effect of such possible roundness which might result, in the long term, from diffusion in the tips of the tetrahedra, we calculated the single-particle eigenenergies of the QD with the external potential set to a linear combination of the spherical Gaussian potential and the tetrahedral Gaussian potential

$$
V_{\text {ext }}(\mathbf{r})=a V_{\text {ext }}^{\text {spher }}(\mathbf{r})+(1-a) V_{\text {ext }}^{\text {tetr }}(\mathbf{r})
$$

where $a \in[0,1]$. The material parameters were those of the $\mathrm{CuGaS}_{2} / \mathrm{CuInSe}_{2}$ material system with the dot size set to the optimal value $L=4.42 \mathrm{~nm}$. This yields the energy spectrum shown in Fig. 21. For comparison, also the energy levels of the linear combinations of the harmonic spherical model potential and the Gaussian spherical model potential are presented.

From Fig. 21 it is apparent that the difference between tetrahedral and spherical Gaussian potential wells lies mainly in the band splitting of the higher states stemming from the lifting of the high symmetry of the sphere. The general tendency upwards in energy is due to the smaller volume of the spherical dot when the radii are equal (the radius of the spherical dot is the insphere radius of the tetrahedron). The lowest four s-like states remain degenerate, but the higher states strongly split. Combined with the inevitable additional splitting due to, e.g., inhomogenous size and shape distribution of the QDs, this will cause a high density of states near the valence band edge.

The states near the valence band edge have an energy separation smaller than $3 k_{B} T$ and this will cause a rapid relaxation of the conduction band electrons through the phonon interaction to the QD states and decrease of the open circuit voltage and the efficiency of the solar cell. The relaxation will continue down to the levels corresponding to the degeneracy of 10 of the harmonic spherical potential well (see Fig. 21). Below this, the separation between the bands is large enough (over $3 k_{B} T$ ) to ensure little thermal occupation. Thus, in the $\mathrm{CuGaS}_{2} / \mathrm{CuInSe}_{2}$ IBSC with the dot radius $4.42 \mathrm{~nm}$ the first three bands will form intermediate bands.

The original IBSC theory assumes only a single IB. Recently, there has been extensions of the theory to multiple intermediate-band solar cells [38]. The presence of multiple IBs reduces the efficiency limit of the IBSC derived from detailed balance calculations, the worst case being when all the IB levels have different quasi-Fermi levels. 


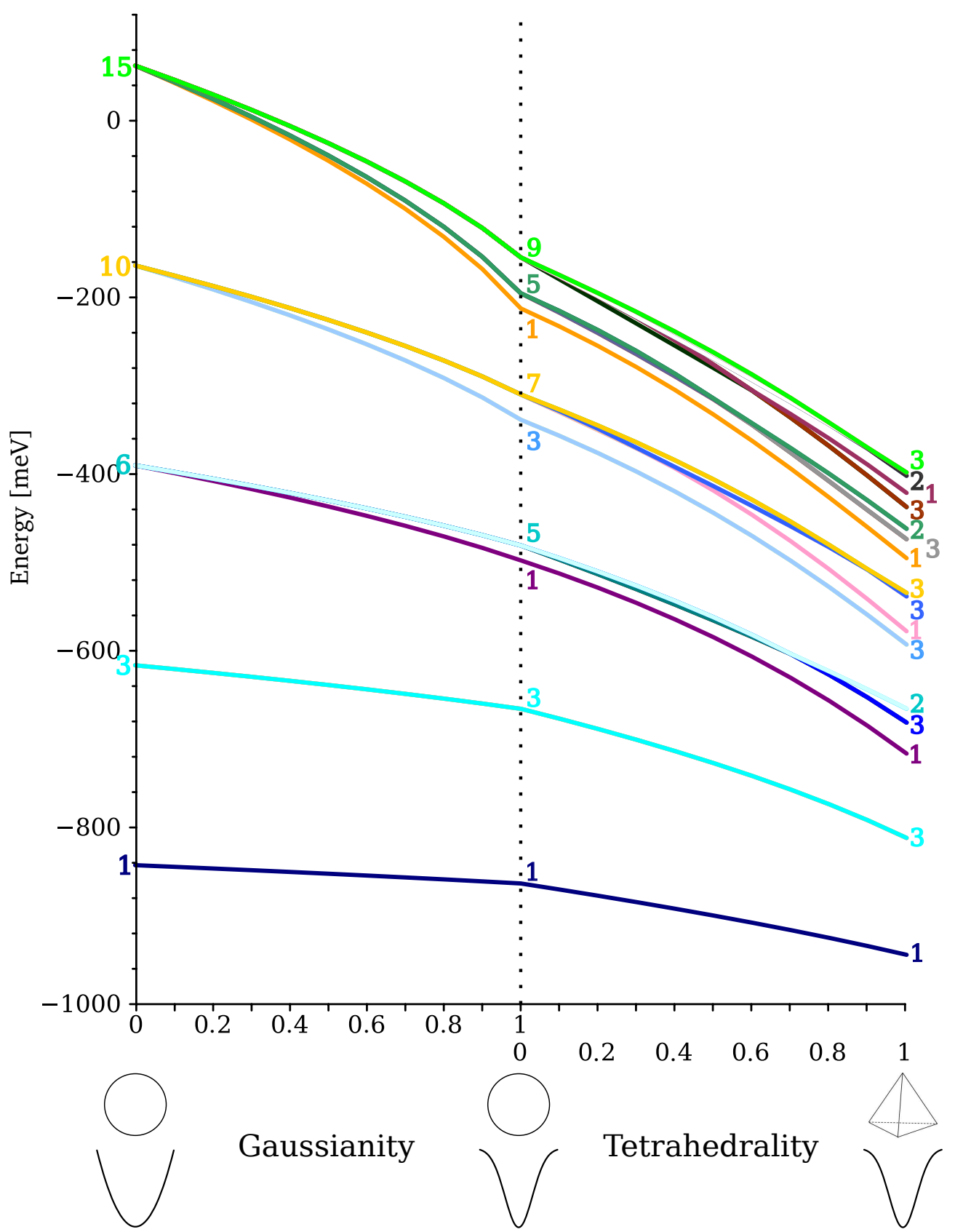

FIGURE 21: Single-particle eigenenergies of the standard harmonic spherical, the Gaussian spherical, and the Gaussian tetrahedral potential wells. 


\subsection{Optical spectra of tetrahedral quantum dots of differing electron numbers}

Optical spectra can be used as a fingerprint for a given system. For this purpose we calculated the optical absorbance of a single QD with different number of electrons. This was done for both material systems, the ZnSe-matrix/CuGaSe ${ }_{2}^{-}$ dots and $\mathrm{CuGaS}_{2}$-matrix/CuInSe${ }_{2}$-dots. The size of the QD in the latter system is the optimum $L_{\mathrm{opt}}=4,42 \mathrm{~nm}$ and in the former the maximum $L_{\max }=1.69 \mathrm{~nm}$ with regard to the thermal occupation limit (see Sec. 6.1).

Figure 22 shows the spectra for $N=1 \ldots 8$ electrons in $\mathrm{CuGaS}_{2}$-matrix/CuInSe $\mathrm{Cu}_{2}$ dots. The absorbance when $N=1$ or $N=2$ is just the energy separation $\left|E_{1}-E_{n}\right|$ where $n>1$. As one adds more electrons more transitions become possible and more peaks appear. The spectra for $N \geq 3$ are remarkably similar and, on the other hand, remarkably different when compared to the spectra for $N<3$. The large difference in the spectra can be used to assess, by optical measurement, whether the number of $\mathrm{QD}$ valence electrons is the desired, that is, about one per QD [39].

Figure 23 shows the spectra for $N=1 \ldots 8$ electrons in the other system, i.e., ZnSe-matrix/CuGaSe ${ }_{2}$-dots. One can immediately see that the spectrum is more disordered than that obtained for the $\mathrm{CuGaS}_{2} / \mathrm{CuInSe}_{2}$ combination. The disorder can be attributed to the relative shallowness of the confining potential which creates a high density of states in the well, and this allows many different transitions. 


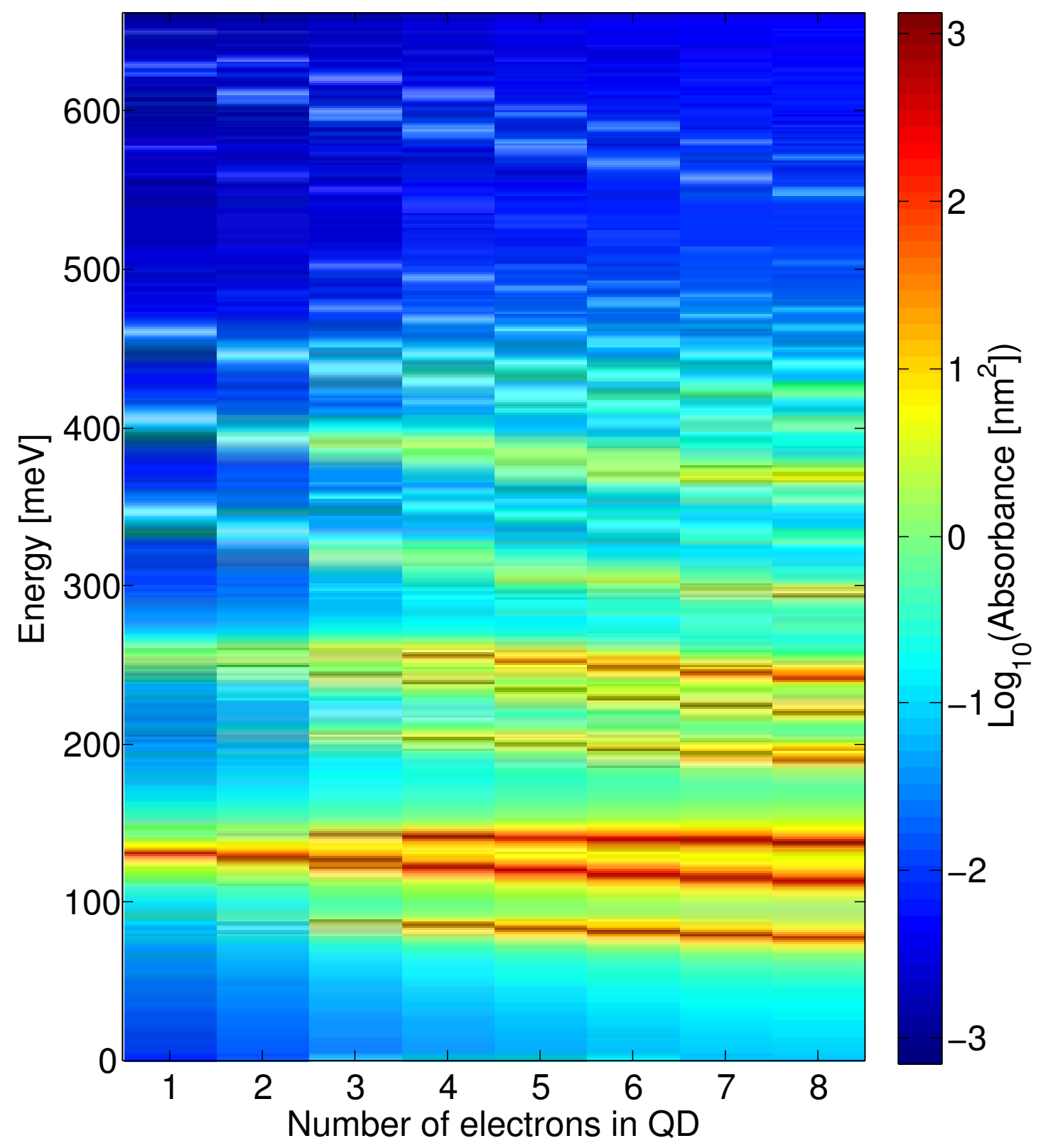

FIGURE 22: Absorption spectra of a single quantum dot for $N=1 \ldots 8$ electrons in the $\mathrm{CuGaS}_{2}$-matrix/CuInSe -dots material combination. 


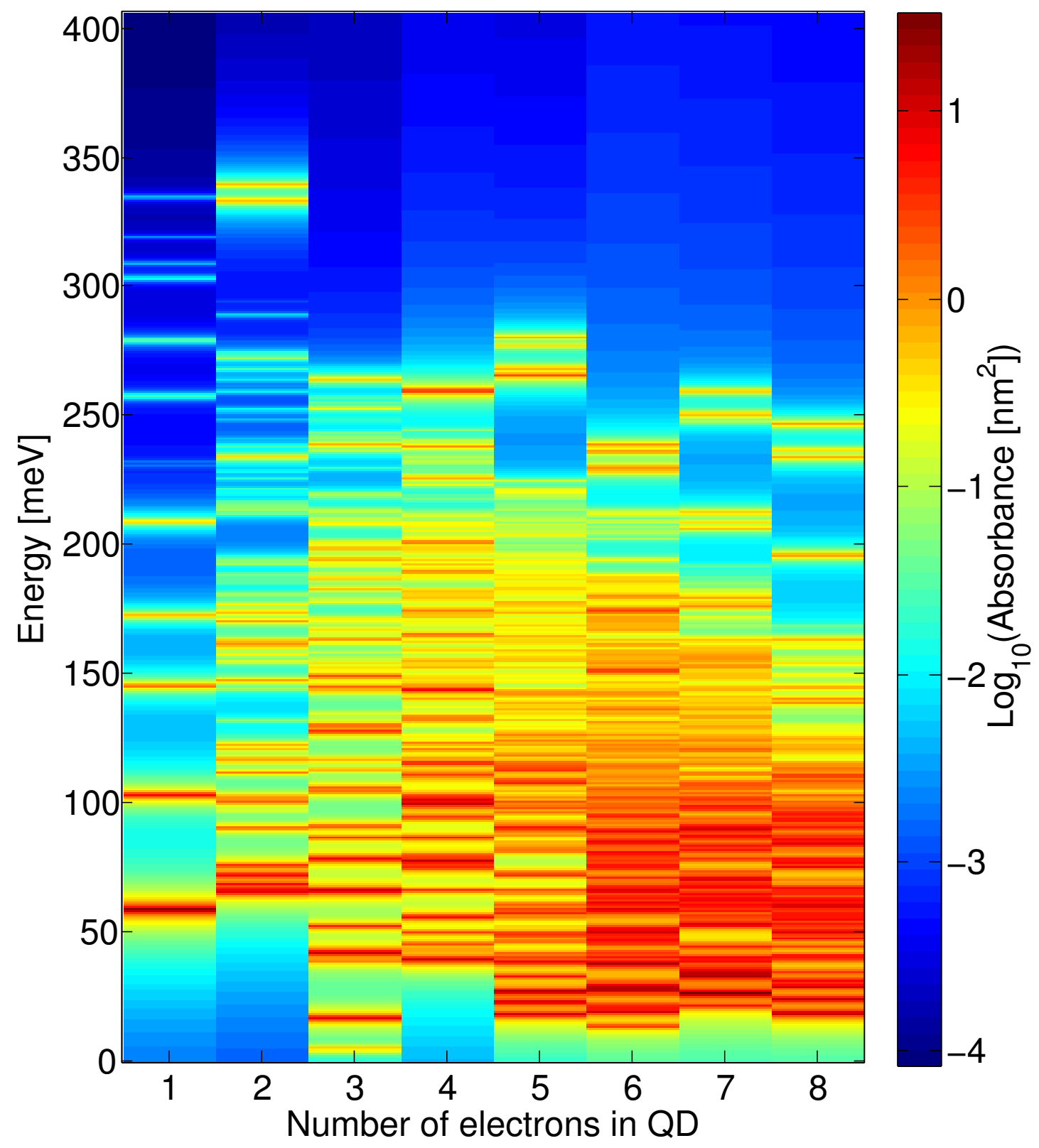

FIGURE 23: Absorption spectra of a single quantum dot for $N=1 \ldots 8$ electrons in the ZnSe-matrix/CuGaSe ${ }_{2}$-dots material combination. 


\subsection{Band structure of stacked quantum dots}

When describing the operation of the IBSC, the IB was assumed to extend itself all over the bulk infermediate band material. But the intermediate levels only exist at the dots and not in the barrier region, unless QDs are placed closely enough that the electron wave function of the dots overlap.

The QDs are often procuded in vertical stacks, where the QD is formed on top of another because of the strain the lower one induces on barrier region. The strain is due to the differing lattice constants of the matrix material and the dot material. This technique has also been applied to IBSCs [40]. For this reason, the density of states of stacked tetrahedral gaussian QDs are presented here. Figure 24 shows the density of states for different separations $\delta$ of the QD centers in the $\mathrm{CuGaS}_{2}$-matrix/CuInSe ${ }_{2}$-dots system. The size of the QD is the optimal size $L=4.42 \mathrm{~nm}$. Separation $\delta=4.0$ corresponds to the case when neigbouring QDs are touching each other. A single electron was placed in each QD.

From Fig. 24 one can see that the states tend to lower energies as the dot separation is made smaller. This is mostly due to the fact that the model potentials of the neighbouring dots are added together, which creates artificially low potentials in the model. The tendency is not due to delocalization effects as could be thought at first sight, which has been checked from the electron density data.

Instead of adding the neighbouring model potentials, a minimum of two overlapping potentials should be taken, as is the standard procedure when simulating double QDs (see Ref. [41] and references therein). Unfortunately, due to the limitations of the Octopus input file syntax and the complexity of the definition of a Gaussian tetrahedral model potential, this was not possible. This limitation will be removed in future works. 


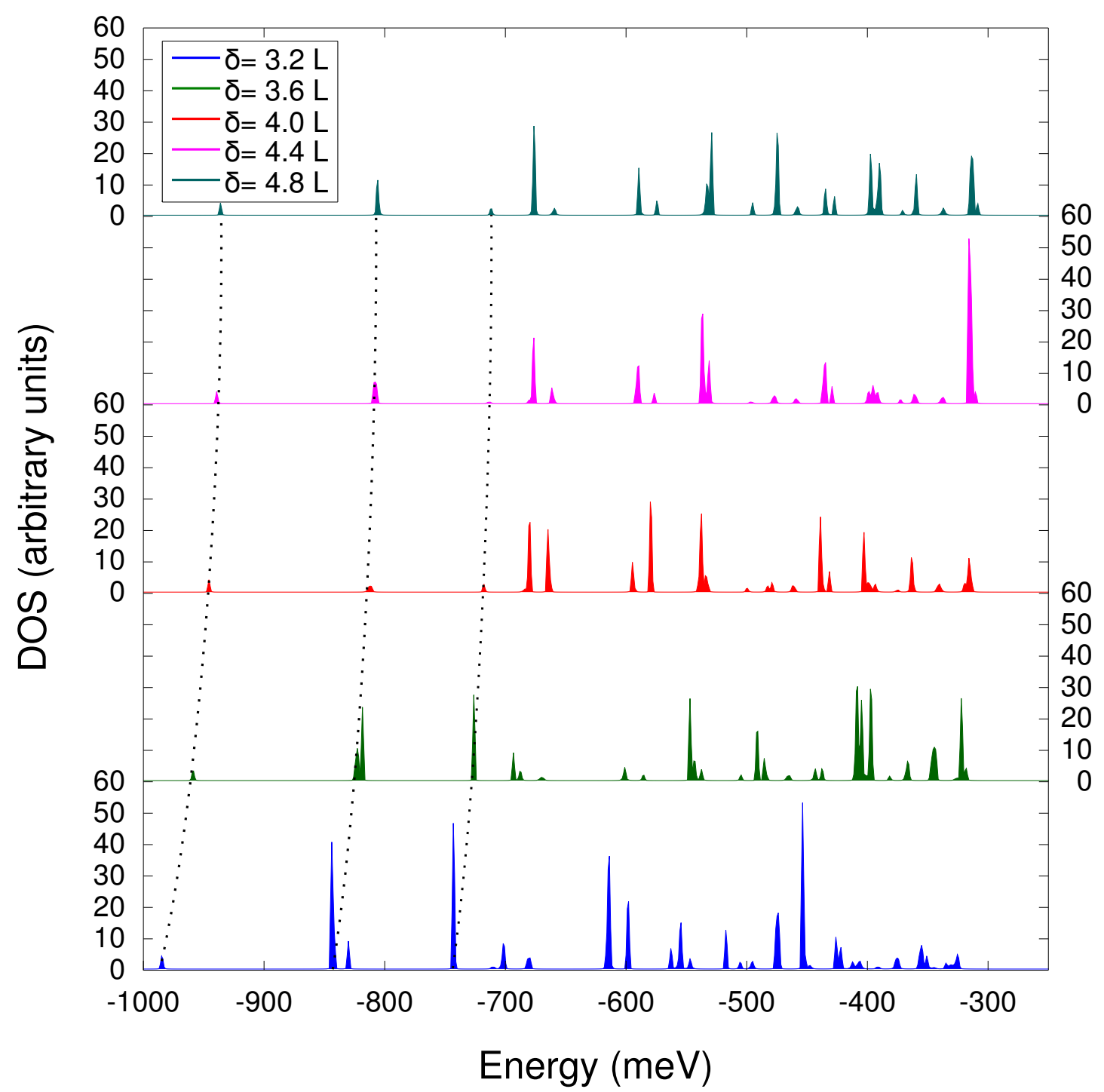

Figure 24: Density of states curves for vertically stacked tetrahedral quantum dots of size $L=4.42 \mathrm{~nm}$ in the $\mathrm{CuGaS}_{2}$-matrix/CuInSe 2 -dots system with five different dot separations. The dashed lines are guides for the eye. 


\section{$9 \quad$ Summary}

We have considered two different chalcopyrite material combinations suggested for intermediate-band solar cell (IBSC) sample fabrication in Helmholtz Zentrum, Berlin. We have obtained the maximum theoretical efficiency values of these two chalcopyrite IBSCs. The optimal sizes of the chalcopyrite quantum dots (QDs) in the corresponding QD-IBSC implementations have been calculated. Optical absorption spectrum of a single chalcopyrite QD has been obtained for both systems. The effect of the QD geometry, especially the effect of the roundness of the QD, was examined. We hope that these results will help in the quest towards more efficient and more affordable solar cells.

\section{References}

[1] A. Luque and A. Martí, "Increasing the efficiency of ideal solar cells by photon induced transitions at intermediate levels," Phys. Rev. Lett., vol. 78, pp. 5014-5017, Jun 1997.

[2] W. Wang, A. S. Lin, and J. D. Phillips, "Intermediate-band photovoltaic solar cell based on znte:o," Applied Physics Letters, vol. 95, no. 1, p. 011103, 2009.

[3] R. M. Swanson, "Photovoltaics power up," Science, vol. 324, 2009. http: //www . sciencemag. org/cgi/content/summary/324/5929/891.

[4] M. Green, "Limits on the open-circuit voltage and efficiency of silicon solar cells imposed by intrinsic auger processes," Electron Devices, IEEE Transactions on, vol. 31, pp. 671 - 678, May 1984.

[5] E. Cartlidge, "Bright outlook for solar cells," IOP - physicsworld.com, July 2007. http://physicsworld.com/cws/article/print/30345.

[6] L. Kazmerski, "Best research-cell efficiencies." National Renewable Energy Laboratory (NREL),http://commons.wikimedia.org/wiki/File: PVeff (rev100921).jpg, September 2010.

[7] A. Luque and S. Hegedus, Handbook of photovoltaic science and engineering. Wiley, 2003.

[8] A. Goetzberger and V. Hoffmann, Photovoltaic solar energy generation. Springer series in optical sciences, Springer, 2005.

[9] Wikipedia, "Monocrystalline silicon — wikipedia, the free encyclopedia," 2010. [Online; accessed 14-December-2010].

[10] M. Toivola, Dye-sensitized solar cells on alternative substrates. PhD dissertation, Aalto University, Department of applied physics, 2010. 
[11] "Aurinkokennot toivat millennium-tiedepalkinnon voiton." Helsingin Sanomat, June 6, 2010.

[12] D. König, K. Casalenuovo, Y. Takeda, G. Conibeer, J. Guillemoles, R. Patterson, L. Huang, and M. Green, "Hot carrier solar cells: Principles, materials and design," Physica E: Low-dimensional Systems and Nanostructures, vol. 42, no. 10, pp. 2862 - 2866, 2010. 14th International Conference on Modulated Semiconductor Structures.

[13] W. A. Tisdale, K. J. Williams, B. A. Timp, D. J. Norris, E. S. Aydil, and X.Y. Zhu, "Hot-Electron Transfer from Semiconductor Nanocrystals," Science, vol. 328, no. 5985, pp. 1543-1547, 2010.

[14] A. Martí, E. Antolín, C. R. Stanley, C. D. Farmer, N. López, P. Díaz, E. Cánovas, P. G. Linares, and A. Luque, "Production of photocurrent due to intermediate-to-conduction-band transitions: A demonstration of a key operating principle of the intermediate-band solar cell," Phys. Rev. Lett., vol. 97, p. 247701, Dec 2006.

[15] A. Martí, L. Cuadra, and A. Luque, "Design constraints of the quantumdot intermediate band solar cell," Physica E: Low-dimensional Systems and Nanostructures, vol. 14, no. 1-2, pp. 150 - 157, 2002.

[16] A. Martí, N. López, E. Antolín, E. Cánovas, C. Stanley, C. Farmer, L. Cuadra, and A. Luque, "Novel semiconductor solar cell structures: The quantum dot intermediate band solar cell," Thin Solid Films, vol. 511-512, pp. 638 -644, 2006. EMSR 2005 - Proceedings of Symposium F on Thin Film and Nanostructured Materials for Photovoltaics - EMRS 2005- Symposium F.

[17] R. Winston, "Light collection within the framework of geometrical optics," J. Opt. Soc. Am., vol. 60, pp. 245-247, Feb 1970.

[18] S. M. Reimann and M. Manninen, "Electronic structure of quantum dots," Rev. Mod. Phys., vol. 74, pp. 1283-1342, Nov 2002.

[19] M. Kelly, Low-dimensional semiconductors: materials, physics, technology, devices. Oxford science publications, Clarendon Press, 1995.

[20] R. Tilley, Crystals and crystal structures. John Wiley, 2006.

[21] S. Siebentritt and U. Rau, eds., Wide-gap chalcopyrites. Springer, 1st edition ed., 2006.

[22] D. F. Marrǿn, A. Martí, and A. Luque, "Thin-film intermediate band photovoltaics: advanced concepts for chalcopyrite solar cells," Physica Status Solidi A, vol. 206, pp. 1021-1025, March 2009.

[23] P. Wagner, "Wachstum und untersuchung von cugase2-basierten nanostrukturen mittels rastersondenmikroskopie," Master's thesis, Technische Universität Berlin, 2009.

[24] W. Schweizer, Numerical quantum dynamics. Progress in theoretical chemistry and physics, Kluwer Academic Publishers, 2001. 
[25] M. G. Burt, "The justification for applying the effective-mass approximation to microstructures," Journal of Physics: Condensed Matter, vol. 4, no. 32, p. 6651, 1992.

[26] P. Hohenberg and W. Kohn, "Inhomogeneous electron gas," Phys. Rev., vol. 136, pp. B864-B871, Nov 1964.

[27] W. Kohn and L. J. Sham, "Self-consistent equations including exchange and correlation effects," Phys. Rev., vol. 140, pp. A1133-A1138, Nov 1965.

[28] M. Marques, Time-dependent density functional theory. Lecture notes in physics, Springer, 2006.

[29] G. E. Scuseria and V. N. Staroverov, "Progress in the development of exchange-correlation functionals," in Theory and Applications of Computational Chemistry (C. E. Dykstra, G. Frenking, K. S. Kim, and G. E. Scuseria, eds.), pp. 669 - 724, Amsterdam: Elsevier, 2005.

[30] J. P. Perdew and K. Schmidt, "Jacob's ladder of density functional approximations for the exchange-correlation energy," AIP Conference Proceedings, vol. 577, no. 1, pp. 1-20, 2001.

[31] E. Runge and E. K. U. Gross, "Density-functional theory for time-dependent systems," Phys. Rev. Lett., vol. 52, p. 997, Mar 1984.

[32] M. E. Casida, "Time-dependent density functional response theory for molecules," Recent advances in Density Functional Methods, vol. 1, pp. 155192, 1995.

[33] X. Andrade, Linear and non-linear response phenomena of molecular systems within time-dependent density functional theory. PhD thesis, Universidad del País Vasco, June 2010.

[34] A. Castro, H. Appel, M. Oliveira, C. A. Rozzi, X. Andrade, F. Lorenzen, M. A. L. Marques, E. K. U. Gross, and A. Rubio, "octopus: a tool for the application of time-dependent density functional theory," Physica status solidi (b), vol. 243, pp. 2465-2488, 2006.

[35] J. E. Jaffe and A. Zunger, "Electronic structure of the ternary chalcopyrite semiconductors cual $s_{2}$, cugas $_{2}$, cuins $s_{2}$, cualse $e_{2}$, cugase $_{2}$, and cuinse $e_{2}, "$ Phys. Rev. B, vol. 28, pp. 5822-5847, Nov 1983.

[36] S. Lankes, M. Meier, T. Reisinger, and W. Gebhardt, "Hole mass determination in znse by observation of standing polariton waves," Journal of Applied Physics, vol. 80, no. 7, pp. 4049-4051, 1996.

[37] J. Adamowski, M. Sobkowicz, B. Szafran, and S. Bedranek, "Electron pair in a gaussian confining potential," Physical Review B, vol. 62, no. 7, pp. 42344237, 2000.

[38] A. Luque, P. G. Linares, E. Antolín, E. Cánovas, C. D. Farmer, C. R. Stanley, and A. Martí, "Multiple levels in intermediate band solar cells," Applied physics letters, vol. 96, p. 013501, January 2010. 
[39] A. Hartmann, Y. Ducommun, E. Kapon, U. Hohenester, C. Simserides, and E. Molinari, "Optical spectra of single quantum dots: Influence of impurities and few-particle effects," Physica Status Solidi (a), vol. 178, p. 283, 2000.

[40] V. Popescu, G. Bester, M. C. Hanna, A. G. Norman, and A. Zunger, "Theoretical and experimental examination of the intermediate-band concept for strain-balanced (in,ga)as/ga(as,p) quantum dot solar cells," Phys. Rev. B, vol. 78, p. 205321, Nov 2008.

[41] A. Putaja and E. Räsänen, "Ultrafast sequential charge transfer in a double quantum dot," Phys. Rev. B, vol. 82, p. 165336, Oct 2010. 